\title{
Lactobacillus reuteri Surface Mucus Adhesins Upregulate Inflammatory Responses Through Interactions With Innate C-Type Lectin Receptors
}

\begin{abstract}
Krisztián P. Bene ${ }^{1 \dagger}$, Devon W. Kavanaugh ${ }^{2 \dagger}$, Charlotte Leclaire ${ }^{2}$, Allan P. Gunning ${ }^{2}$, Donald A. MacKenzie ${ }^{2}$, Alexandra Wittmann ${ }^{3}$, lan D. Young ${ }^{3}$, Norihito Kawasaki ${ }^{3}$, Eva Rajnavolgyi ${ }^{1 *}$ and Nathalie Juge ${ }^{2 *}$
\end{abstract}

\begin{abstract}
${ }^{1}$ Department of Immunology, Faculty of Medicine, University of Debrecen, Debrecen, Hungary, ${ }^{2}$ The Gut Health and Food Safety Programme, Institute of Food Research, Norwich, UK, ${ }^{3}$ Food and Health Programme, Institute of Food Research, Norwich, UK
\end{abstract}

\section{OPEN ACCESS}

Edited by: Alexandre Morrot, Federal University of Rio de Janeiro,

Brazil

Reviewed by: Tiago W. P. Mineo,

Federal University of Uberlandia, Brazi Alessandra D' Almeida Filardy, Federal University of Rio de Janeiro,

Brazil

*Correspondence:

Nathalie Juge

nathalie.juge@ifr.ac.uk

Eva Rajnavolgyi

evaraj@med.unideb.hu

†These authors are joint first authors.

Specialty section: This article was submitted to Microbial Immunology, a section of the journal

Frontiers in Microbiology

Received: 03 October 2016

Accepted: 15 February 2017

Published: 07 March 2017

Citation:

Bene KP, Kavanaugh DW, Leclaire C, Gunning AP, MacKenzie DA, Wittmann A, Young ID, Kawasaki N, Rajnavolgyi E and Juge N (2017) Lactobacillus reuteri Surface Mucus Adhesins Upregulate Inflammatory Responses Through Interactions With Innate C-Type Lectin Receptors.

Front. Microbiol. 8:321. doi: 10.3389/fmicb.2017.00321
The vertebrate gut symbiont Lactobacillus reuteri exhibits strain-specific adhesion and health-promoting properties. Here, we investigated the role of the mucus adhesins, CmbA and MUB, upon interaction of L. reuteri ATCC PTA 6475 and ATCC 53608 strains with human monocyte-derived dendritic cells (moDCs). We showed that mucus adhesins increased the capacity of $L$. reuteri strains to interact with moDCs and promoted phagocytosis. Our data also indicated that mucus adhesins mediate antiand pro-inflammatory effects by the induction of interleukin-10 (IL-10), tumor necrosis factor alpha (TNF- $\alpha), I L-1 \beta, I L-6$, and IL-12 cytokines. L. reuteri ATCC PTA 6475 and ATCC 53608 were exclusively able to induce moDC-mediated Th1 and Th17 immune responses. We further showed that purified MUB activates moDCs and induces Th1 polarized immune responses associated with increased IFN $\gamma$ production. MUB appeared to mediate these effects via binding to C-type lectin receptors (CLRs), as shown using cell reporter assays. Blocking moDCs with antibodies against DC-specific intercellular adhesion molecule 3-grabbing non-integrin (DC-SIGN) or Dectin-2 did not affect the uptake of the MUB-expressing strain, but reduced the production of TNF$\alpha$ and IL- 6 by moDCs significantly, in line with the Th1 polarizing capacity of moDCs. The direct interaction between MUB and CLRs was further confirmed by atomic force spectroscopy. Taken together these data suggest that mucus adhesins expressed at the cell surface of $L$. reuteri strains may exert immunoregulatory effects in the gut through modulating the Th1-promoting capacity of DCs upon interaction with C-type lectins.

Keywords: L. reuteri, probiotic, mucus adhesins, dendritic cells, C-type lectins, DC-SIGN, Dectin-2, T-lymphocytes

\section{INTRODUCTION}

The gastrointestinal (GI) tract harbors a vast and diverse community of commensal bacteria (microbiota) which has co-evolved with the host (Walter and Ley, 2011). The gut microbiota provides a range of benefits to the host including the digestion of complex carbohydrates, production of metabolites, detoxification, protection against pathogens, and the development 
and regulation of the immune system (Sun and Chang, 2014). The intestinal immune system negotiates a delicate balance between immunogenicity against invading pathogens and tolerance to the commensal microbiota (Mann and Li, 2014). Lactobacillus reuteri is a common inhabitant of the GI tract of vertebrates and displays remarkable host adaptation. L. reuteri has diversified into separate phylogenetic clades reflecting host origin (Oh et al., 2010) with genomic differences reflecting the niche characteristics of the host GI tract (Frese et al., 2011). We previously reported that the adhesion of $L$. reuteri strains to mucus is strain-specific, correlating with the presence of hostclade mucus-binding proteins (MacKenzie et al., 2010; Etzold et al., 2014b). L. reuteri adhesins include mucus-binding proteins, MUB (Roos and Jonsson, 2002; MacKenzie et al., 2009, 2010; Etzold et al., 2014a) and CmbA (Jensen et al., 2014; Etzold et al., 2014b), and serine-rich-repeat (SRR) proteins (Frese et al., 2013; Wegmann et al., 2015). L. reuteri exhibits strainspecific beneficial properties relevant to human health, including exclusion and inhibition of the growth of intestinal pathogens, maintenance of the gut barrier integrity, and modulation of the host immune system at both local and systemic levels (as reviewed in Walter et al., 2011).

Dendritic cells (DCs) are pivotal in the initiation of adaptive immune responses and can directly contact and internalize intestinal bacteria (Rescigno et al., 2001). Further, DCs can undergo tissue conditioning by intestinal epithelial cells that control the DC inflammatory potential (Iliev et al., 2009). Accordingly, the intestinal milieu represents a unique environment conditioned by all-trans retinoic-acid (ATRA), where metabolite production is increased by peroxisome proliferator-activated receptor gamma $(\operatorname{PPAR} \gamma)$ in both $\mathrm{CD}^{-}{ }^{-}$ $\mathrm{CD}^{+} \mathrm{d}^{+}$human monocyte-derived DCs (moDCs) in vitro (Szatmari et al., 2006; Gogolak et al., 2007) and in human intestinal DCs (Gyöngyösi et al., 2013). T-lymphocytes primed by DCs with monocyte precursors play an important role in the maintenance of self-tolerance against gut commensal bacteria (Persson et al., 2013). DCs use pattern recognition receptors (PRRs), such as Toll-like receptors (TLRs) or C-type lectin receptors (CLRs) to sense various microbe-associated molecular patterns (MAMPs). In the gut, DCs are able to distinguish between different members of the microbiota (Diebold, 2009; Feng et al., 2012) and drive the activation and differentiation of naive T-lymphocytes into either effector (Th1, Th17) or regulatory $\mathrm{T}$ cells (Treg) (Geijtenbeek and Gringhuis, 2009; Rescigno, 2014). In addition, the nature of T-lymphocyte polarizing signals is largely determined by the type of microbial products, inflammatory signals, or both encountered in peripheral tissues during the immature phase (Geijtenbeek and Gringhuis, 2009; Hooper and Macpherson, 2010; Rescigno, 2014).

L. reuteri has been shown to have immunomodulatory properties and promote mucosal tolerance in the vertebrate GI tract. Specific probiotic strains of $L$. reuteri were recently shown to suppress intestinal inflammation in a trinitrobenzene sulfonicacid (TNBS)-induced mouse colitis model via down-regulation of gene expression of the mucosal cytokine IL- 6 and IL-1 $\beta$ in the colon (Gao et al., 2015). L. reuteri 100-23 stimulated the development of an increased number of regulatory $\mathrm{T}$ cells in mice (Livingston et al., 2010). Immunomodulation was also reported in piglets following oral administration of $L$. reuteri I5007, resulting in an increased level of TGF- $\beta$ and a decrease in IFN $\gamma$ gene expression in the mesenteric lymph nodes (Hou et al., 2015). In humans, L. reuteri ATCC 55730 was shown to temporarily colonize the stomach and the small intestine of healthy subjects and thus increase $\mathrm{CD} 4^{+}$helper T-lymphocyte numbers in the ileum (Valeur et al., 2004). However, the modulation of cytokine production by L. reuteri appears to be strain-dependent, as demonstrated in vitro. For example, antiinflammatory L. reuteri strains ATCC PTA 6475 and ATCC PTA 5289 , but not the immuno-stimulatory $L$. reuteri strains ATCC 55730 and CF48-3A, suppressed TNF- $\alpha$ production induced by bacterial lipopolysaccharide (LPS)-activated monocytic cells (Lin et al., 2008; Jones and Versalovic, 2009). Moreover, a recent study showed that $L$. reuteri strains from human-associated clades differed in their ability to modulate human cytokine production (TNF- $\alpha$, monocyte chemoattractant protein-1 (MCP-1), IL-1 $\beta$, IL-5, IL-7, IL-12, and IL-13) by myeloid cells (Spinler et al., 2014). The bacterial molecule(s) responsible for down-regulating TNF- $\alpha$ in antigen presenting cells have not been identified to date but appear to be strain-specific (Lin et al., 2008; Jones and Versalovic, 2009).

Recently, it was suggested that cell-surface proteins may play a role in regulating the immunomodulatory properties of lactobacilli (Lebeer et al., 2008; Meijerink et al., 2010; Remus et al., 2013; Call et al., 2015; Jensen et al., 2015). However, the detailed molecular mechanisms by which $L$. reuteri may interact with DCs to modulate immune responses and promote mucosal homeostasis are not well understood. The aim of this work was to investigate the role of $L$. reuteri strain-specific mucus adhesins on the modulation of pro- and anti-inflammatory cytokine production by human moDCs and the participation of CLRs in this process.

\section{MATERIALS AND METHODS}

\section{Bacterial Strains and Reagents}

L. reuteri ATCC PTA 6475 and L. reuteri ATCC PTA 6475 lar_0958 KO mutant (6475-KO) (Etzold et al., 2014b), and L. reuteri ATCC 53608 and $1063 \mathrm{~N}$ isolates (MacKenzie et al., 2010) were used in this study. The anti-Mub antibody is described in MacKenzie et al. (2010). SIGN-R1 was purchased from Sino Biological (Beijing, China), DC-SIGN from CaltagMedsystems Ltd (Buckingham, UK), and Dectin-1 and Dectin-2 from R\&D Systems (Abingdon, UK). The anti-human Dectin2 (HDECT2) IgG was from Invitrogen (Toulouse, France) and the DC-SIGN/CD209 mAb (clone 120507) from Abcam, (Cambridge, UK).

\section{Human moDC Cultures}

Leukocyte-enriched buffy coats were obtained from healthy blood donors at the Regional Blood Center of the Hungarian National Blood Transfusion Service (Debrecen, Hungary) in accordance with the written approval of the Director of 
the National Blood Transfusion Service of the University of Debrecen, Faculty of Medicine (Hungary). Peripheral blood mononuclear cells (PBMCs) were separated by a standard density gradient centrifugation with Ficoll-Paque Plus (Amersham Biosciences, Uppsala, Sweden). Monocytes were purified from PBMCs by positive selection using immunomagnetic cell separation using anti-CD14 microbeads, according to the manufacturer's instruction (Miltenyi Biotec, Bergisch Gladbach, Germany). After separation on a VarioMACS magnet, 96-99\% of the cells were shown to be $\mathrm{CD}_{14}{ }^{+}$monocytes, as measured by flow cytometry. Isolated monocytes were cultured in 12 -well tissue culture plates at a density of $5.0 \times 10^{5}$ cells/ml in Gibco's serum-free AIM-V medium (Invitrogen, Carlsbad, CA, USA), supplemented with $80 \mathrm{ng} / \mathrm{ml}$ granulocytemonocyte stimulating factor (GM-CSF) (Gentaur Molecular Products, Brussels, Belgium) and $100 \mathrm{ng} / \mathrm{ml}$ interleukin-4 (IL-4) (PeproTech EC, London, UK). The cells were differentiated in the presence or absence of 1 nM ATRA (Sigma-Aldrich, Schnelldorf, Germany) at $37^{\circ} \mathrm{C}$ atmosphere containing $5 \% \mathrm{CO}_{2}$.

\section{Phagocytosis Assay}

Live bacterial cells were centrifuged at $1000 \times g$ for 5 min and washed three times in $25 \mathrm{ml}$ phosphate buffered saline (PBS). Suspensions of bacterial cells were heat inactivated by heating at $65^{\circ} \mathrm{C}$ for $45 \mathrm{~min}$ and re-suspended in $0.25 \mathrm{M}$ carbonatebicarbonate buffer $(\mathrm{pH}$ 9.0). The bacterial cell suspensions $(900 \mu \mathrm{l})$ were stained with $100 \mu \mathrm{l}$ fluorescein-isothiocyanate (FITC) dissolved at $5 \mathrm{mg} / \mathrm{ml}$ in dimethyl-sulfoxide (DMSO) and were rotated overnight at $4^{\circ} \mathrm{C}$ in dark. FITC-labeled bacteria were washed three times with cold PBS and were co-incubated for $3 \mathrm{~h}$ with $\mathrm{moDCs}$ at $37^{\circ} \mathrm{C}$ or $4^{\circ} \mathrm{C}$ at a moDC:bacteria ratio of $1: 20$. The moDCs positive for FITC-labeled bacteria were analyzed by flow cytometry.

\section{Growth of Bacteria for moDC Activation}

L. reuteri strains were grown in Difco ${ }^{\mathrm{TM}}$ de Man, Rogosa and Sharpe (MRS) broth medium for $18 \mathrm{~h}$ stationary at $37^{\circ} \mathrm{C}$ (MRS, BD BioSciences, Franklin Lakes, NJ, USA). Bacterial suspensions were washed with $25 \mathrm{ml}$ sterile PBS buffer three times and $\mathrm{OD}_{600 \mathrm{~nm}}$ was measured by spectrophotometry and converted to cell $/ \mathrm{ml}$ following $\mathrm{OD}_{600 \mathrm{~nm}} \times 2.5 \times 10^{8} \mathrm{CFU} / \mathrm{ml}$ (Regulski et al., 2012). Human moDC cultures were activated with LPS as control ( $250 \mathrm{ng} / \mathrm{ml}$ ultrapure LPS, InvivoGen, 3950 Sorrento Valley Blvd, San Diego, CA, USA) or with live L. reuteri strains at a non-toxic ratio of $0.4: 1$ bacteria:moDCs and were co-cultured for another 24 or $1.5 \mathrm{~h}$.

\section{Flow Cytometry Analysis}

Phenotyping of resting and activated moDCs was performed by flow cytometry using anti-HLA-DR-PE (BD Biosciences), antiCD80-FITC, anti-CD83-FITC, anti-CD86-PE (R\&D Systems, Minneapolis, MN, USA) and isotype-matched control antibodies. To block non-specific antibody binding, heat-inactivated mouse serum was used. Fluorescence intensities were measured by FACS Calibur (BD Biosciences). The data were analyzed by the FlowJo software version 5.7.1 (Tree Star, Ashland, OR, USA).

\section{Measurement of Cytokine Concentrations}

Culture supernatants of moDCs were harvested $24 \mathrm{~h}$ after moDC activation, and the concentration of TNF- $\alpha$, IL- $1 \beta$, IL- 6 , IL-10, IL12(p70) and IL-23(p19) cytokines was measured using OptEIA kits (BD Biosciences, Franklin Lakes, NJ, USA) following the manufacturer's instructions.

\section{Measurement of the Polarization of IFN $\gamma$ and IL-17-Producing T-Lymphocytes}

Activated moDCs were washed and co-cultured with peripheral blood lymphocytes (PBLs) for 4 days in AIM-V medium at moDC:T-cell ratios of 1:20. IFN $\gamma$ and IL-17 secretion was analyzed using the avidin-horseradish peroxidase based enzyme-linked ImmunoSpot (ELISPOT) system (NatuTec GmbH, Herriotstrasse 1, 60528 Frankfurt am Main. Germany). Lymphocytes activated by phytohaemagglutinin or concanavalin A were used as positive controls, the co-cultures containing resting moDCs and T-cells, or T-cells alone served as negative controls. To detect IL-17 secretion, the plates were coated with $0.5 \mu \mathrm{g} / \mathrm{ml}$ murine anti-human CD3 antibody (BD Biosciences). The plates were analyzed by using the ImmunoScan plate reader (Cell Technology Limited, Shaker Heights, OH, USA).

\section{MUB Purification}

L. reuteri ATCC 53608 was inoculated from $-80^{\circ} \mathrm{C}$ glycerol stocks into the semi-defined substrate medium, LDMII (Kotarski and Savage, 1979) under anaerobic conditions for $16 \mathrm{~h}$ at $37^{\circ} \mathrm{C}$, followed by sub-culture at $0.1 \%(\mathrm{v} / \mathrm{v})$ for $24 \mathrm{~h}$ at $37^{\circ} \mathrm{C}$ to stationary phase. Cells were removed by centrifugation at $7,500 \times g$ for $15 \mathrm{~min}$ at $4^{\circ} \mathrm{C}$. Spent culture medium was further purified by vacuum-filtration through $0.45 \mu \mathrm{m}$ and $0.22 \mu \mathrm{m}$ filter disks (Merck Millipore, Nottingham, UK), sequentially, and concentrated by tangential flow filtration using Vivaflow 200 cassettes (100,000 Da molecular weight cut-off; Sartorius Stedim, Surrey, UK). The spent culture was further purified by gel filtration chromatography using a Superose 6 GL 10/300 column (GE Healthcare, Little Chalfont, UK) with PBS as eluent. To fractionate MUB from co-purifying glycolipid, CHAPS (3-[(3-cholamidopropyl)dimethylammonio]1-propanesulfonate; Sigma Aldrich, Darmstadt, Germany) was added to $0.5 \%(\mathrm{w} / \mathrm{v})$ to both the sample and eluent during gel filtration. The MUB protein (predicted size of $353 \mathrm{kDa}$ ) was eluted in the void volume of the column with and without the addition of CHAPS and its purity was confirmed by SDS-PAGE. Before use, MUB was dialyzed extensively against PBS using Vivaspin 6 spin filters (100 kDa; Sartorius Stedim Ltd, Surrey, $\mathrm{UK})$ to remove CHAPS.

\section{Endotoxin Removal}

The MUB protein solution was further purified according to the protocol of Zhang et al. (2005). Briefly, Lipid Removal Adsorbent ( $2 \%$ w/v; Sigma Aldrich, Darmstadt, Germany) was added to the MUB solution and was incubated under gentle rotation for $2 \mathrm{~h}$ at $4^{\circ} \mathrm{C}$. The mixture was then centrifuged at 5,000 $\times g$ for $10 \mathrm{~min}$ at $4^{\circ} \mathrm{C}$ and the supernatant collected and stored at $4^{\circ} \mathrm{C}$ until use. 


\section{Cell Reporter Assay}

BWZ.36 cells expressing murine C-type lectins receptors (CLRs), mouse Dectin-1 (mDectin-1), and SIGN-R1 were established as described previously for mouse Dectin-2 (mDectin-2) (Wittmann et al., 2016). Briefly, the extracellular domain of mDectin-1 (Ser74 through Leu244) and SIGN-R1 (Ser76 through Gly324) were cloned separately into the retrovirus vector pMXsIRES-EGFP-Ly49A-CD3 $\zeta$ encoding transmembrane region of the mouse Ly49A and the cytoplasmic domain of the mouse CD3 $\zeta$ (Wittmann et al., 2016). The resulting pMXs vectors encoding mDectin-1 and SIGN-R1, respectively, were used for the retrovirus transduction using Plat-E cells (Wittmann et al., 2016). In order to introduce two amino acid mutations into the carbohydrate-binding domain of SIGN-R1 (E285Q and D287N), a DNA fragment encoding the extracellular domain of SIGN-R1 with the two missense mutations was synthesized (Genscript) and used for cloning as above.

To assess the binding of MUB or lipid component to CLRs, ligands were adsorbed onto 96-well microplates (Nunc) overnight at $4^{\circ} \mathrm{C}$. The MUB protein was added at $0.1 \mathrm{mg} / \mathrm{ml}$ in PBS, and the lipid fraction co-purified with the MUB protein was diluted with PBS at a ratio of 1:1 before adsorption to the plate. Scleroglucan $(1 \mu \mathrm{g} / \mathrm{ml})$ (ELICITYL), $\alpha$-mannan $(2 \mu \mathrm{g} / \mathrm{ml})$ (Sigma-Aldrich), and Hafnia-LPS $(1 \mu \mathrm{g} / \mathrm{ml})$ (a gift from Dr. Ewa Katzenellenbogen, Ludwik Hirszfeld Institute of Immunology and Experimental Therapy, Wroclaw, Poland) were used as specific ligands for mDectin1, mDectin-2 and SIGN-R1, respectively. Wells were washed twice with PBS, and reporter cells $\left(1 \times 10^{6}\right.$ cells $\left./ \mathrm{ml}\right)$ and were added to each well and incubated for $18 \mathrm{~h}$ at $37^{\circ} \mathrm{C}, 5 \% \mathrm{CO}_{2}$. Following incubation, the microwell plates were centrifuged at $510 \times g$ for $3 \mathrm{~min}$ and the supernatant was discarded. $\beta$-galactosidase activity (encoded by the lac $Z$ reporter gene) was determined by the addition of $200 \mu \mathrm{L}$ of $150 \mathrm{mM}$ chlorophenol red- $\beta$-D-galactopyrasonide (CPRG; Roche) diluted in a CPRG assay reaction buffer (PBS supplemented with $0.125 \%$ Triton X-100 and $100 \mathrm{mM}$ 2-mercaptoethanol, Lonza) to each well. The plate was incubated for $45 \mathrm{~min}$ at $37^{\circ} \mathrm{C}, 5 \% \mathrm{CO}_{2}$ prior to measurement of color development (A570/630 nm) with a Bio-Rad Benchmark Plus microtiter plate reader.

\section{Adhesion Measurements by Force Spectroscopy}

The interactions between MUB and CRLs were examined by covalently attaching the MUB molecules to atomic force microscopy (AFM) tips and DC-SIGN or SIGN-R1 or Dectin-2 to the glass slides to enable binding interactions to be measured in a specific manner (Hinterdorfer et al., 2002). Silicon nitride AFM tips (PNP-TR, Nanoworld AG, Neuchâtel, Switzerland) and freshly cleaned glass slides were functionalized using a four step procedure (carried out at $21^{\circ} \mathrm{C}$ ): the first step involved incubation in a $2 \%$ solution of 3-mercaptopropyltrimethoxy silane (MTS, Sigma-Aldrich, Poole, Dorset, UK) in toluene (dried over a $4 \AA$ molecular sieve) for $2 \mathrm{~h}$, followed by washing with toluene and then chloroform. In the second step, the silanised tips were incubated for $1 \mathrm{~h}$ in a $1 \mathrm{mg} / \mathrm{ml}$ solution of a heterobifunctional linker: MAL-PEG-SCM, 2 kD (Creative PEGWorks, Chapel Hill, NC, USA) in chloroform. The silanised glass slides were incubated in $5 \mathrm{mM} \mathrm{N}$ - $\gamma$-maleimidobutyryl-oxysuccinimide ester (GMBS) in ethanol (Thermo Fisher Scientific, Waltham, MA, USA). The tips and slides were rinsed with chloroform/ethanol, respectively, and then dried with argon. The third step involved covalent attachment of the molecules investigated in this study (i.e., CLRs and MUB) by incubation of the tips/slides in $1 \mathrm{mg} / \mathrm{ml}$ solutions of the proteins in PBS at $\mathrm{pH} 7.4$ for $1 \mathrm{~h}$ at $21^{\circ} \mathrm{C}$, followed by a PBS washing step. The fourth step involved incubation of the functionalized cantilevers/slides in a $10 \mathrm{mg} / \mathrm{ml}$ solution of glycine in PBS to 'amine'-cap any unreacted succinimide groups, followed by washing in PBS.

Binding measurements were carried out in PBS using a MFP3D BIO AFM (Asylum Research Inc., Santa Barbara, CA, USA). The experimental data were captured in 'force-volume' (FV) mode at a rate of $2 \mu \mathrm{m} / \mathrm{s}$ in the $\mathrm{Z}$ direction and at a scan rate of $1 \mathrm{~Hz}$ and a maximum load force of $300 \mathrm{pN}$ (pixel density of $32 \times 32$ ). The spring constant, $\mathrm{k}$, of the cantilevers was determined by fitting the thermal noise spectra (Hutter and Bechhoefer, 1993), yielding typical values in the range 0.03$0.06 \mathrm{~N} / \mathrm{m}$. Adhesion in the force spectra was quantified using a bespoke Excel macro (Gunning et al., 2008) which fits a straight line to the baseline of the retract portion of the forcedistance data. In order to explore the specificity of the binding interactions, the force measurements were repeated after addition of $0.05 \mathrm{mg} / \mathrm{ml}$ anti-Mub antibody (MacKenzie et al., 2010) to the liquid cell.

\section{In vitro Detection of CLR-Mediated Inflammatory Responses}

To assess the role of CLRs in the induction of moDC-mediated inflammatory cytokine release, endotoxin-free purified MUB was coated to sterile high protein-affinity OptEIA ELISA 96-well plates (BD Biosciences) at $38.5 \mu \mathrm{g} / \mathrm{ml}$ concentration followed by overnight incubation at $4^{\circ} \mathrm{C}$. After repeated washing steps with sterile PBS, the cells were co-incubated with moDCs in the presence or absence of $5 \mu \mathrm{g} / \mathrm{ml}$ anti-Dectin-2 monoclonal antibody (clone Q7-4B5 InvivoGen) or anti-DC-SIGN (120507 Abcam, Cambridge, UK) antibody for $1 \mathrm{~h}$ on ice. After the washing steps with $5 \mathrm{ml}$ fresh AIM-V medium $2 \times 10^{5}$ moDCs were cultured in microwell plastic plates for $24 \mathrm{~h}$ coated or uncoated with MUB. The concentration of TNF- $\alpha$ and IL- 6 cytokines was measured in the culture supernatants using OptEIA kits. In another set of experiments, moDCs were first co-incubated with blocking antibodies specific for Dectin-2 or DC-SIGN and following a washing step with fresh AIM-V medium, the cells were co-cultured with $L$. reuteri ATCC 53608 or $1063 \mathrm{~N}$ strains for $1.5 \mathrm{~h}$ at $37^{\circ} \mathrm{C}$ at a moDC:bacteria ratio of 1:4. The supernatant was removed by centrifugation at $1000 \mathrm{rpm}$ for $5 \mathrm{~min}$ and the cells washed repeatedly with $5 \mathrm{ml} \mathrm{PBS}$ at $4^{\circ} \mathrm{C}$ (five times) followed by centrifugation at $1000 \mathrm{rpm}$. Finally, the moDCs were co-cultured with autologous T-lymphocytes in AIMV medium for 4 days at a moDC:T-cell ratio of 1:20. The secretion of IFN $\gamma$ was analyzed by ELISPOT assay. T-lymphocytes co-cultured with either resting moDCs, bacteria or culture media served as negative controls. 


\section{Statistical Analysis}

Student's unpaired two-tailed $t$-test or ANOVA followed by Bonferroni's multiple comparison tests were used as indicated in the relevant experiments. In case of significantly different variances $(p<0.05)$ between the sample sets the Welch's correction was applied in the $t$-test. The results were expressed as mean + SD. All analyses were performed by using the GraphPad Prism software, version 6.0. Differences were considered to be statistically significant at $P<0.05$. Significance was indicated as ${ }^{*} P<0.05$; $^{* *} P<0.01 ;{ }^{* * *} P<0.005 ;{ }^{* * * *} P<0.0001$.

\section{RESULTS}

\section{Mucus Adhesins Facilitate the Phagocytosis of $L$. reuteri Strains by moDCs}

The L. reuteri strains ATCC PTA 6475 and ATCC 53608 (1063) express mucus-binding proteins $\mathrm{CmbA}$ (Jensen et al., 2014; Etzold et al., 2014b) and MUB (Etzold et al., 2014a; MacKenzie et al., 2010), respectively on their cell surface. It is well established that the phagocytic process of bacteria can modulate the outcome of immune responses. To assess the impact of mucus adhesins on the internalization of $L$. reuteri strains by moDCs, we used L. reuteri mutant strains, $L$. reuteri $6475-\mathrm{KO}$ (Jensen et al., 2014; Etzold et al., 2014b) and 1063N (MacKenzie et al., 2010) deficient for $\mathrm{CmbA}$ and MUB, respectively, in comparison to the wild-type strains. In these experiments, the moDCs isolated from PBMCs of healthy blood donors were cultured in serum-free medium in the presence or absence of ATRA.

When the FITC-labeled strains were incubated with moDCs at $37^{\circ} \mathrm{C}$ for $1.5 \mathrm{~h}$, the L. reuteri $1063 \mathrm{~N}$ MUB-mutant was internalized 10-fold less efficiently than its wild-type counterpart ATCC 53608, and the engulfment of ATCC PTA 6475 was twofold more efficient than that of the $6475-\mathrm{KO} \mathrm{CmbA}$ mutant strain (Figures 1A,C). Moreover, there were significant differences $(p=0.0142)$ between mutant strains with a 10 fold decreased level of internalized $1063 \mathrm{~N}$ mutant strain as compared to the $6475-\mathrm{KO}$ strain. At $4^{\circ} \mathrm{C}$, the phagocytic process was significantly inhibited but the ratio of adherent bacteria was higher in the wild-type strains as compared to the mutants (Figure 1B). The presence of ATRA inhibited the cell surface expression of CD1a, resulting in $\mathrm{CD}^{-} \mathrm{a}^{-} \mathrm{CD}^{+} \mathrm{d}^{+}$ moDCs (data not shown) but no difference could be detected in the $L$. reuteri phagocytic capacity of the cells as compared to moDCs differentiated in the absence of ATRA. Taken together, these results demonstrate that the cell-surface expressed mucus adhesins have the potential to promote the internalization process by moDCs.

\section{Mucus Adhesins Modulate moDC-Mediated Immune Responses to L. reuteri Strains}

The moDC activating potential of L. reuteri ATCC PTA 6475 and ATCC 53608, as well as their mutant strains, was further analyzed by measuring the cell surface expression of CD83, the co-stimulatory molecules CD80 and CD86, and the major histocompatibility complex (MHC) class II-protein, HLA-DR, by flow cytometry. We showed that the cell surface expression of CD83 was induced by all $L$. reuteri strains, however, in the presence of the $1063 \mathrm{~N}$ mutant, CD83 expression was reduced significantly, suggesting a potential role of MUB in moDC activation (Figures $2 \mathrm{~A}, \mathrm{D}$ ). Co-culturing moDCs with $L$. reuteri strains for $24 \mathrm{~h}$ also induced cell surface expression of the costimulatory molecules CD80 and CD86 (Figure 2B) and HLADR (Figure 2C). However, the co-stimulatory potential was exclusively reduced by $1063 \mathrm{~N}$.

The level of moDC-derived pro-inflammatory cytokines (TNF- $\alpha$, IL-1 $\beta$, IL-6) and that of the T-lymphocyte polarizing cytokines (IL-10, IL-12, IL-23) was monitored upon incubation with wild-type and mutant $L$. reuteri strains. L. reuteri ATCC PTA 6475 induced TNF- $\alpha$ secretion more efficiently than ATCC 53608. The $6475-\mathrm{KO}$ and $1063 \mathrm{~N}$ mutants induced lower levels of TNF- $\alpha$ production than their wild-type counterparts (Figure 3A). The L. reuteri $1063 \mathrm{~N}$ mutant was further associated with lower IL-1 $\beta$, IL-6 and anti-inflammatory IL-10 production as compared to the wild-type ATCC 53608 strain (Figure 3B). Interestingly, both $L$. reuteri wild-type ATCC PTA 6475 and mutant $6475-\mathrm{KO}$ induced the secretion of immunoregulatory IL-10 in moDCs to a similar extent whereas the production of the inflammatory cytokines (TNF- $\alpha$, IL-1 $\beta$, IL-6) was reduced in presence of $6475-\mathrm{KO}$. In addition, all $L$. reuteri strains tested in these experiments provoked potent IL-12 and IL-23 cytokine responses as compared to the LPS control (Figure 3C). These results demonstrated that mucus adhesins expressed by $L$. reuteri strains have the potential to enhance pro-inflammatory cytokine production in moDCs.

Next we addressed the question whether moDC-mediated T-cell responses targeting $L$. reuteri mucus adhesin-expressing strains were able to orchestrate T-lymphocyte polarization. In this context, moDCs were first exposed to L. reuteri strains or to LPS used as a control, followed by co-culturing the cells with autologous T-lymphocytes for 4 days. The secretion of IFN $\gamma$ and IL-17 cytokines was monitored at a single cell level by using the ELISPOT assay with IFN $\gamma$ or IL-17 specific monoclonal antibody-coated plates. MoDCs activated by the ATCC PTA 6475 or ATCC 53608 wild-type strains induced IFN $\gamma$ secretion by T-lymphocytes (Figure $\mathbf{4 A}$ ) and resulted in increased IL-17 production (Figure 4B), as compared to the immature moDC:Tcell co-cultures. In contrast, the L. reuteri $6475-\mathrm{KO}$ and $1063 \mathrm{~N}$ mutant strains induced IFN $\gamma$ producing Th1 cell activation, but were unable to trigger IL-17 polarized immune responses. Taken together, these results demonstrate that mucus adhesins are able to up-regulate immune responses against $L$. reuteri strains in moDCs.

\section{Purified Mucus-Binding Protein (MUB) Triggers CD83 Expression and Provokes Th1 Polarized Immune Responses in moDCs}

To further characterize the immunomodulatory potential of L. reuteri strains, native MUB was purified from $L$. reuteri ATCC 


\section{A}

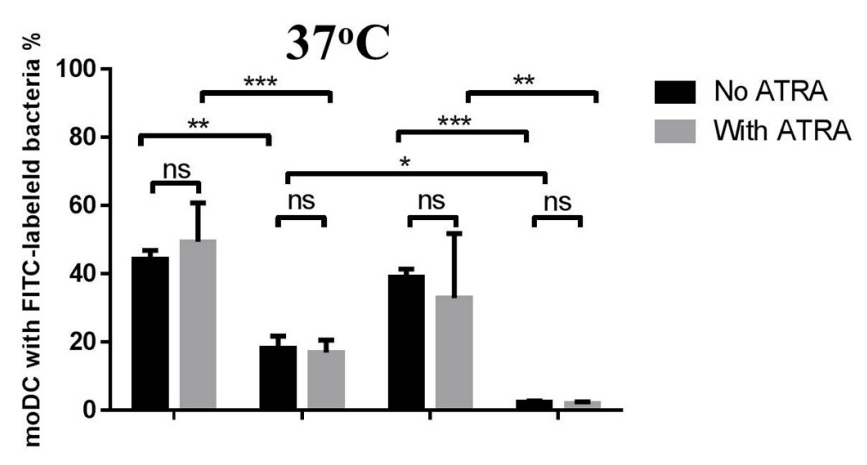

B

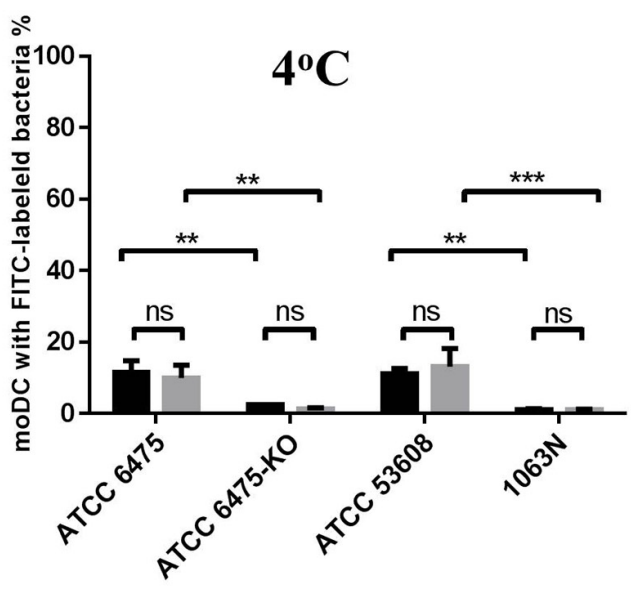

C

No ATRA

With ATRA

ATCC 6475 ATCC 53608

ATCC 6475 ATCC 53608

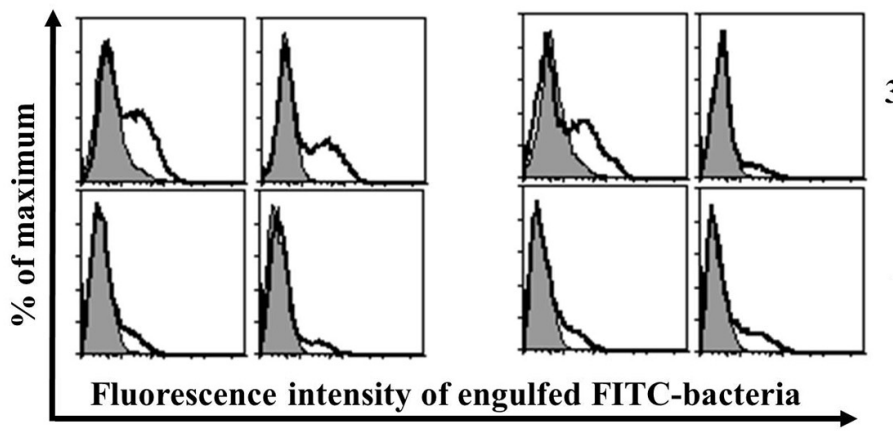

$3^{\circ} \mathrm{C}$

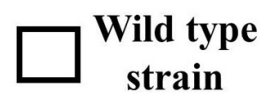

Mutant strain

FIGURE 1 | The phagocytic capacity of moDCs co-cultured with $\boldsymbol{L}$. reuteri is strain-dependent. Human moDCs were differentiated in the presence of GM-CSF, IL-4 and with or without $1 \mathrm{nM}$ ATRA for 2 days. On day 2, moDCs were co-cultured with heat-inactivated bacteria at $37^{\circ} \mathrm{C}(\mathbf{A})$ or at $4^{\circ} \mathrm{C}$ (B) for $1.5 \mathrm{~h}$ at a moDC:bacteria ratio of 1:20. Bacterial uptake was measured by flow cytometry. The number of moDC carrying phagocytosed FITC-labeled bacteria was calculated from 3 independent experiments + SD. Histogram overlays are shown for one independent experiment (C). Statistical differences were analyzed by ANOVA, with significance defined as ${ }^{*} P<0.05,{ }^{*} P<0.01,{ }^{* * *} P<0.001$, and ${ }^{* * * *} P<0.0001$.

53608 spent culture medium, either associated with glycolipids, or separated from the glycolipid fraction when CHAPS was employed (Supplementary Figure S1). We investigated the inflammatory nature of purified, endotoxin-free MUB as compared to LPS, and also the glycolipid fraction in the course of the moDC-regulated immune response. Increasing concentrations of purified MUB induced CD83 expression on the moDC surface (Figures $\mathbf{5 A}, \mathbf{C}$ ). The cell surface expression of the
CD80 co-stimulatory molecule was also enhanced independent of MUB concentration, although this effect did not reach statistical significance (Figures 5B,C). The level of moDC-secreted proinflammatory cytokines, including TNF- $\alpha$, IL-1 $\beta$, IL-6, IL-12 and the anti-inflammatory cytokine IL-10 was dependent on the concentration of MUB, except in the case of IL-6. When moDCs were cultured in the presence of 0.5 or $1 \mu \mathrm{g} / \mathrm{ml} \mathrm{MUB}$, the production of IL-10 cytokine, known to have regulatory potential, 
A

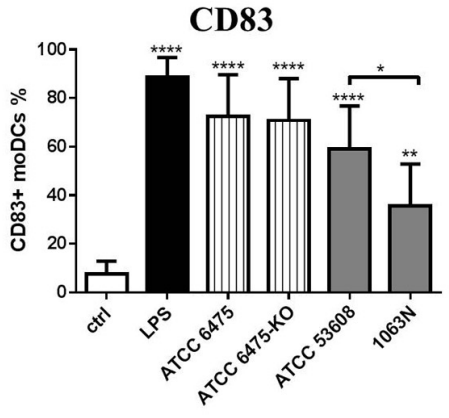

C

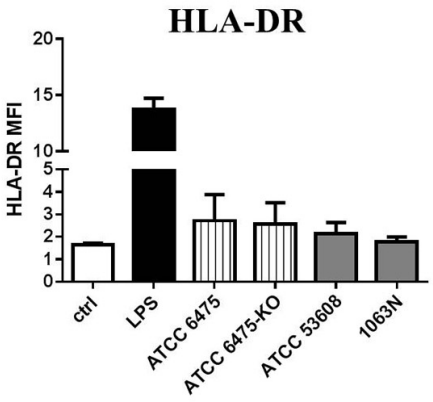

B

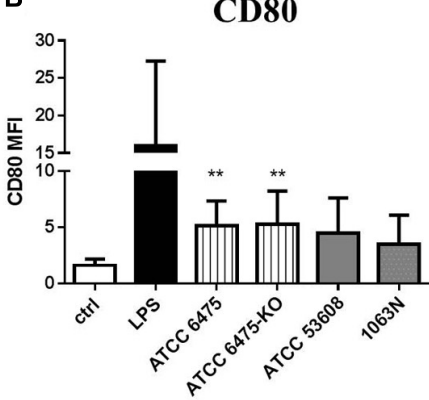

CD86

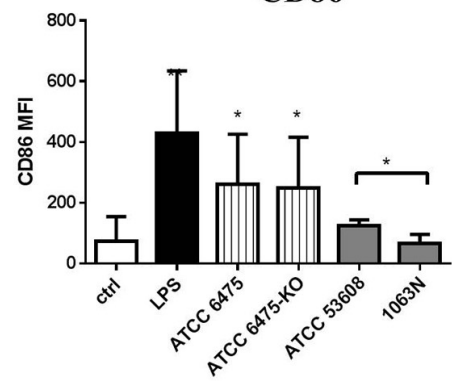

D

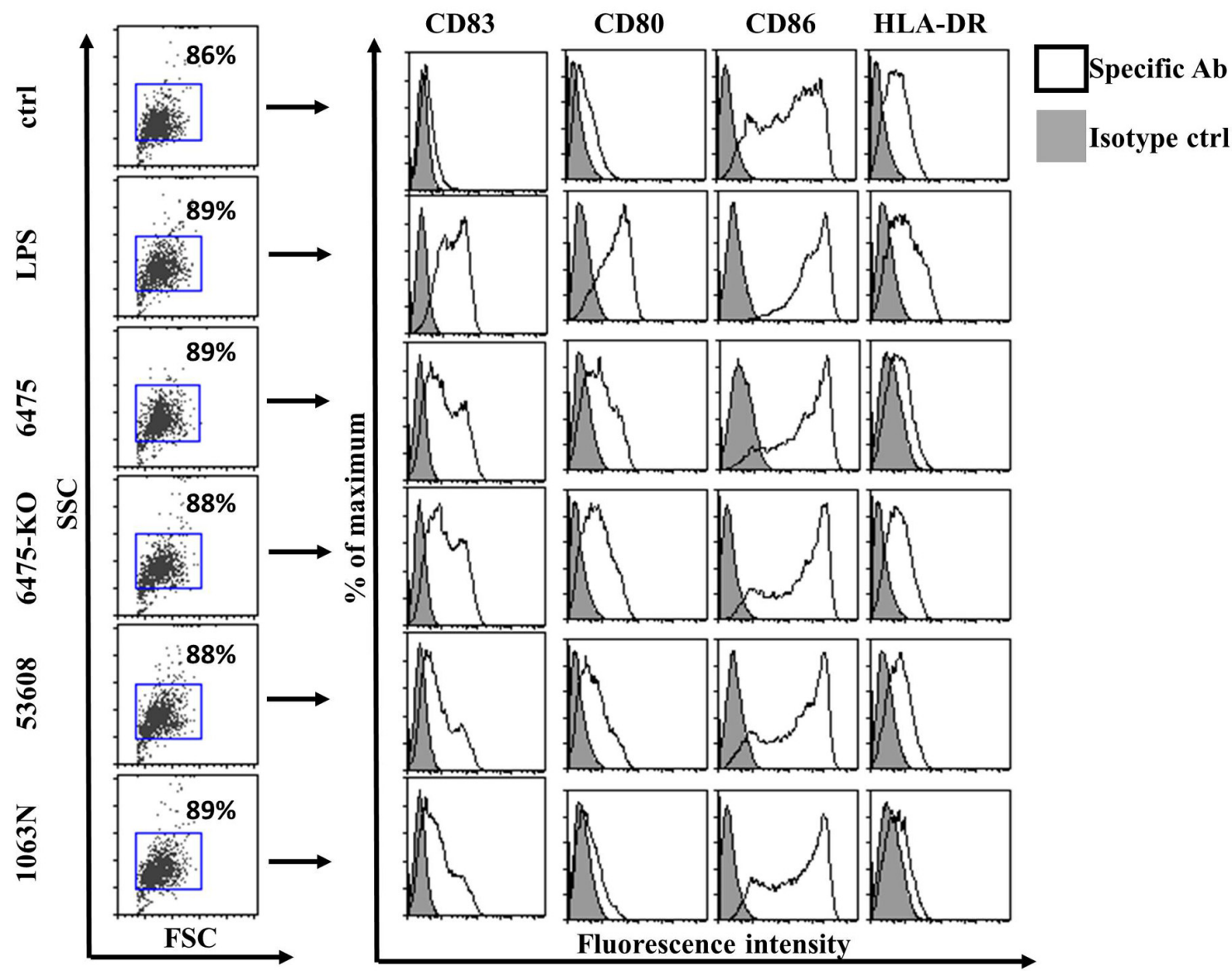

FIGURE 2 | L. reuteri strains modulate the expression of cell surface activation markers in moDC. MoDCs were co-incubated with live $L$. reuteri strains, or LPS as a control, for $24 \mathrm{~h}$. The expression of moDC-associated activation marker CD83 (A), co-stimulatory molecules CD80 and CD86 (B) and MHC class II-protein, HLA-DR (C) was measured by flow cytometry. Mean values were calculated from 5 to 7 independent experiments \pm SD. Histogram overlays are shown for one independent experiment (D). Statistical differences were analyzed by Student's $t$-test, with significance defined as ${ }^{*} P<0.05,{ }^{* *} p<0.01,{ }^{* * *} P<0.001$, and **** $P<0.0001$. 
$\mathbf{A}$

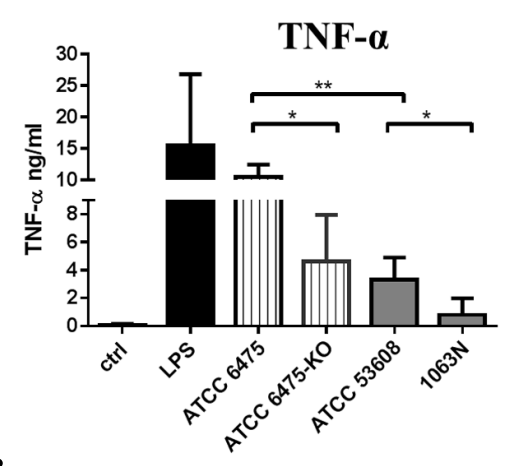

B

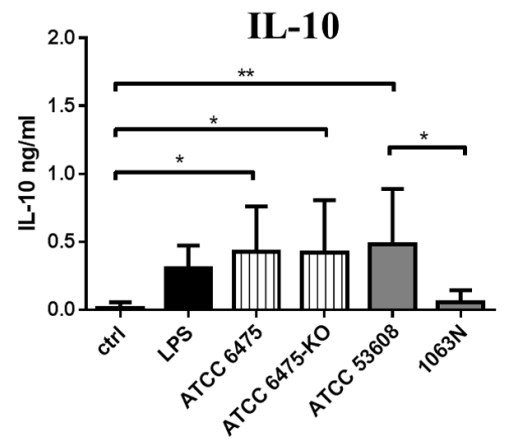

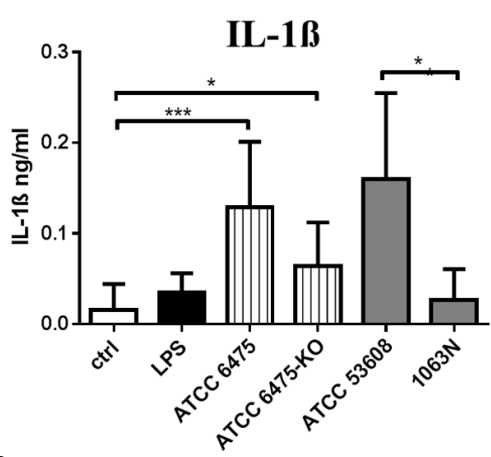

C

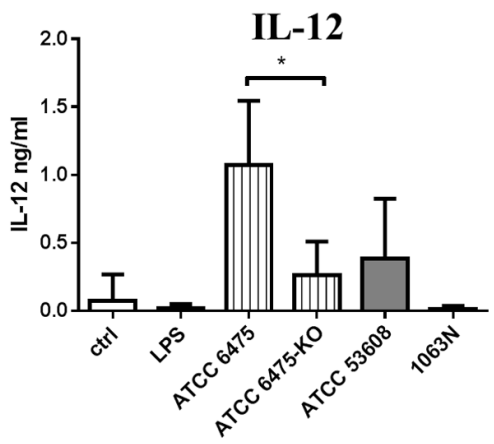

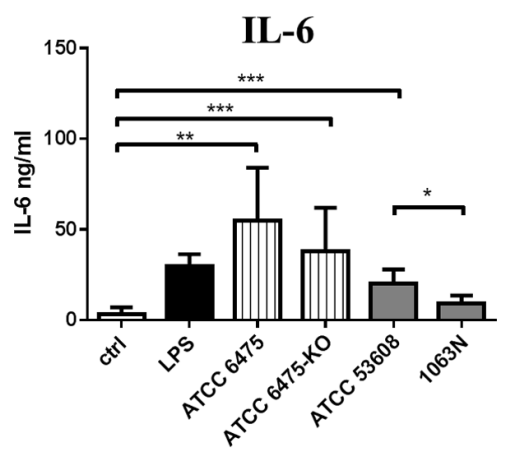

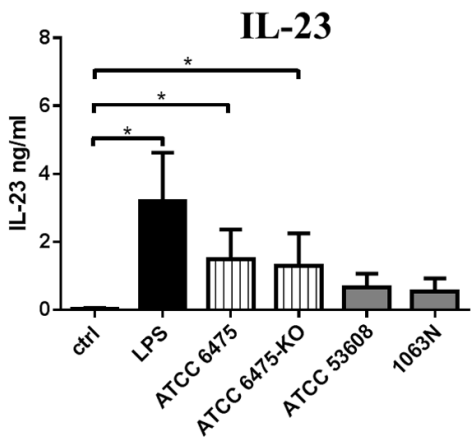

FIGURE 3 | The secretion of inflammatory and regulatory cytokines is modified in a $L$. reuteri strain-dependent manner in moDCs. MoDCs were co-incubated with L. reuteri strains, or with LPS as a control, for 24 h. The concentration of TNF $\alpha, I L-1 \beta$, IL-6, (A) IL-10 (B), IL-12, IL-23 (C) cytokines was measured by ELISA in 5 independent experiments. Mean values \pm SD are shown. Statistical differences were analyzed by Student's $t$-test, with significance defined as ${ }^{*} P<0.05,{ }^{* *} P<0.01,{ }^{* * *} P<0.001$, and ${ }^{* * * *} P<0.0001$

was found to be in the logarithmic range of $0.01-0.1 \mathrm{ng} / \mathrm{ml}$, while the concentration of the pro-inflammatory cytokine IL-12 varied within the $0.1-1 \mathrm{ng} / \mathrm{ml}$ range (Figure 5D). Furthermore, moDC cultures activated with LPS or MUB induced Th1 polarized immune responses associated with increased IFN $\gamma$ production (Figure 5E), in line with the increased concentration of IL12. ATRA had no effect on the purified MUB-induced moDC response (data not shown). The extracted lipid fraction also induced CD83 and CD86 expression on the moDC cell surface to a similar extent as induced by the lipid containing MUB fraction (Supplementary Figure S2A). However, pure MUB lacking glycolipids was associated with the reduced secretion of IL-12 and was unable to induce IL-23 production by moDCs (Supplementary Figure S2B). Furthermore, the lipid fraction was unable to induce IL-12 or IL-23 production, suggesting that the immunogenicity of MUB can be enhanced by the lipid component of this fraction.

\section{The Immunomodulatory Properties of MUB Are Mediated by DC-SIGN and Dectin-2 Interactions in moDC}

To gain insight into the mechanisms mediating the interaction of MUB with moDCs, we first tested the binding of MUB to reporter cells expressing specific CLRs on the cell surface. MUB significantly bound to murine mDectin-2 and SIGN-R1 (murine analog of human DC-SIGN) reporter cells in a dose-dependent manner (Figure 6A). There was no binding to the mock cells (used as a negative control) and we could not detect any binding of MUB to mDectin-1 using the same approach. When MUB was incubated with reporter cells expressing the mDectin-2 QPD mutant, in which the mannose-binding activity was eliminated by substituting EPN (glutamic acid-proline-asparagine) sequence into galactose-type QPD, the binding was reduced, indicating the specificity of the interaction. Interestingly, the lipid fraction showed strong interaction with the SIGN-R1 receptor, at a level similar to that of the positive control, Hafnia alvei LPS, which has $\alpha$-linked mannan $O$-antigen (Wittmann et al., 2016). The binding of MUB to CLRs was further investigated by atomic force spectroscopy. In this experiment, MUB was covalently linked to the functionalized AFM tip, and the CRLs were immobilized onto the glass slide, taking advantage of specific covalent attachment chemistry (Bhatia et al., 1989). The modal value of binding strength $(684 \mathrm{pN})$ revealed a strong interaction between MUB and DC-SIGN (Figure 6B). The addition of anti-Mub antibody to the liquid cell significantly inhibited the interaction. The presence of highly symmetrical negative peaks in both force magnitude and distance indicates sequential unfolding of Mub multiple repeats as DC-SIGN and MUB are pulled apart (CarrionVazquez et al., 1999) (Figure 6C). The number of unfolding events was significantly reduced in the presence of anti-Mub antibody (Figure 6C). Figures 6D,E show the quantification 


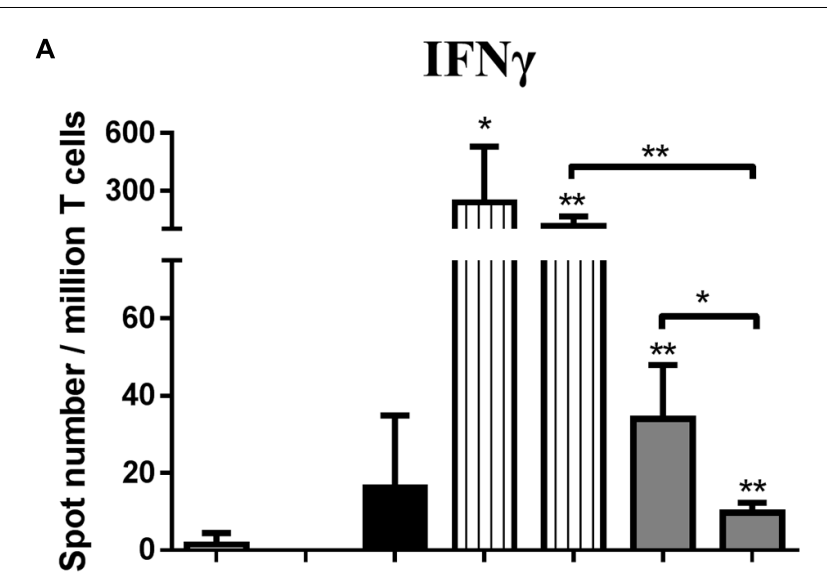

B

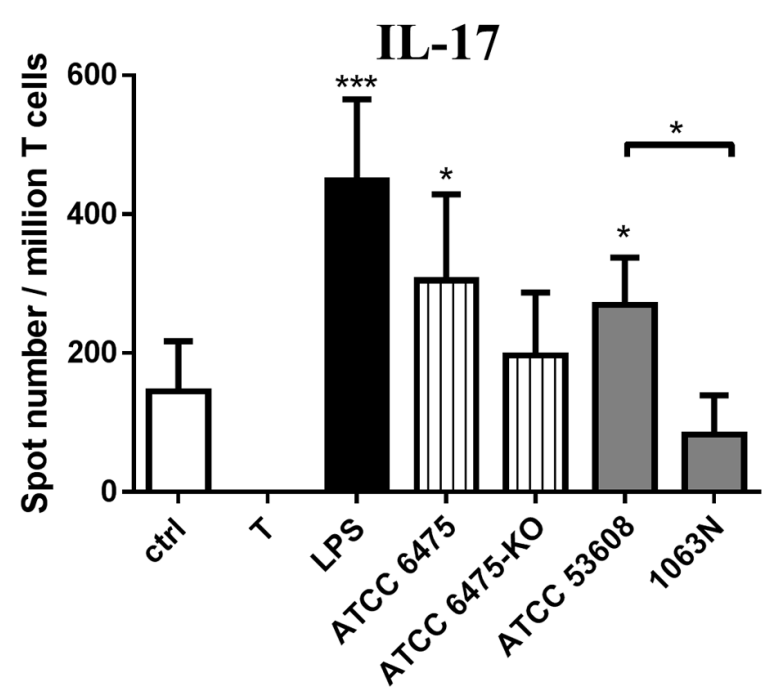

FIGURE 4 | L. reuteri mucus adhesins modulate moDC-mediated T-lymphocyte polarization. The T-cell activating and polarizing capacity of moDCs was monitored by activating moDCs with $L$. reuteri strains or LPS followed by co-culture with T-cells. T corresponds to T-cells cultured without dendritic cells as negative control. The mean values of spot numbers were calculated from five independent experiments + SD. The number of cytokine-producing $T$-lymphocytes induced by LPS or moDCs exposed to L. reuteri strains was measured by ELISPOT assays for IFN $($ (A) and IL-17 (B). Statistical differences were analyzed by Student's $t$-test, with significance defined as ${ }^{*} P<0.05,{ }^{* *} P<0.01,{ }^{* * *} P<0.001$, and ${ }^{* * * *} P<0.0001$.

of the binding interactions between MUB and SIGN-R1 or Dectin-2, respectively.

To gain further insights into the enhanced inflammatory response induced by bacterial MUB in moDCs, we analyzed the role of selected CLRs, Dectin-2 and DC-SIGN, upon MUBmoDC interaction. We found that immobilized MUB activated the secretion of pro-inflammatory cytokine TNF- $\alpha$ and IL-6 (Figure 7A) and this effect could be prevented in moDCs efficiently by neutralizing the signal transducer function of Dectin-2 and DC-SIGN receptors with blocking antibodies to DC-SIGN or Dectin-2, while IL-1 $\beta$ and IL-12 cytokine production was not detected (data not shown). Interestingly, we found that $L$. reuteri uptake was not eliminated in moDCs in the presence of anti-DC-SIGN or anti-Dectin-2 antibodies (data not shown). To confirm the involvement of Dectin-2 and DCSIGN in the activation of moDC-mediated T-cell differentiation, blocking antibodies targeting these cell surface CLRs were used in the presence of L. reuteri ATCC 53608 and $1063 \mathrm{~N}$ (Figure 7B). The Th1 polarizing capacity of moDCs induced by the wildtype strain was reduced in presence of anti-Dectin-2 or antiDC-SIGN antibodies as compared to CLR-unblocked moDCs. As expected, the Th1 polarizing capacity of the mutant strain $1063 \mathrm{~N}$ was not affected by blocking DC-SIGN and Dectin-2 on moDCs. These results clearly demonstrate that the interaction of Dectin-2 and DC-SIGN with MUB presented by L. reuteri ATCC 53608 is crucial to acquire Th1-cell differentiation upon bacterial stimulation of moDCs.

\section{DISCUSSION}

Probiotic lactobacilli, as part of the healthy microbiota, have been reported to regulate mammalian cytokine production and intestinal inflammation in various experimental model systems (van Baarlen et al., 2013). However, it is also clear that the immunomodulatory effects of probiotic strains such as L. reuteri are strain-dependent, exerting different DC activation patterns in vitro. For example, L. reuteri strains ATCC PTA 6475 and ATCC PTA 5289 were reported to suppress the production of TNF- $\alpha$ by LPS-activated monocytic cells (Lin et al., 2008; Jones and Versalovic, 2009), whereas the L. reuteri strains ATCC 55730 and CF48-3A were shown to have an immuno-stimulatory effect (Lin et al., 2008; Jones and Versalovic, 2009). A similar down-regulation of pro-inflammatory cytokines (e.g., TNF- $\alpha$ ) by L. reuteri ATCC PTA 6475 was also observed with primary monocyte-derived macrophages from children with Crohn's disease (Peña et al., 2005). Christensen et al. (2002) showed that the L. reuteri DSM 12246 strain was a poor inducer of IL-12, TNF$\alpha$, and IL-6 in bone marrow-derived murine DCs. Moreover, a more recent study showed that $L$. reuteri strains from humanassociated clades differed in respect to their ability to modulate human cytokine production (TNF- $\alpha$, monocyte chemoattractant protein-1 (MCP-1), IL-1 $\beta$, IL-5, IL-7, IL-12, and IL-13) by stimulated myeloid cells (Spinler et al., 2014). Although not well understood, it is likely that the sum of bacterial cell surfacederived and soluble factors and/or exopolysaccharides (EPS) contribute to the development of different immune responses induced by $L$. reuteri strains. For example, soluble factors of L. reuteri CRL1098 were able to reduce TNF- $\alpha$ production by human PBMCs (Mechoud et al., 2012) and in mouse models (Griet et al., 2014). Furthermore, human moDCs generated in the presence of the soluble factors of L. reuteri DSM 17938 downmodulated LPS-induced IL-6, IL-10, and IL-23 secretion while the secretion of regulatory cytokine TGF- $\beta$ remained unaffected (Haileselassie et al., 2016). EPS isolated from L. reuteri strain DSM 17938 and L26 Biocenol ${ }^{\mathrm{TM}}$ was recently shown to exert up-regulation of the mRNA level of IL- $1 \beta$, NF- $\kappa B$, TNF- $\alpha$, and IL-6 (Kšonžeková et al., 2016). One of the putative L. reuteri 
A

B

CD83 CD80

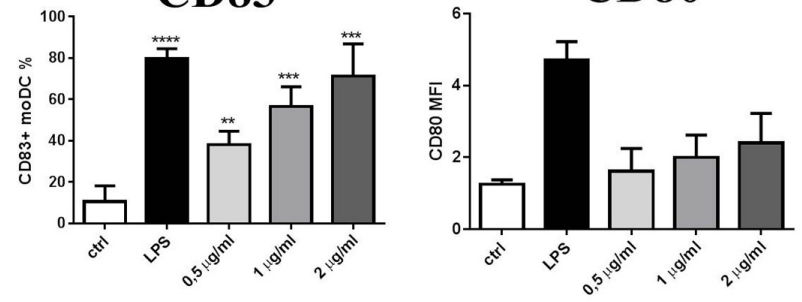

C

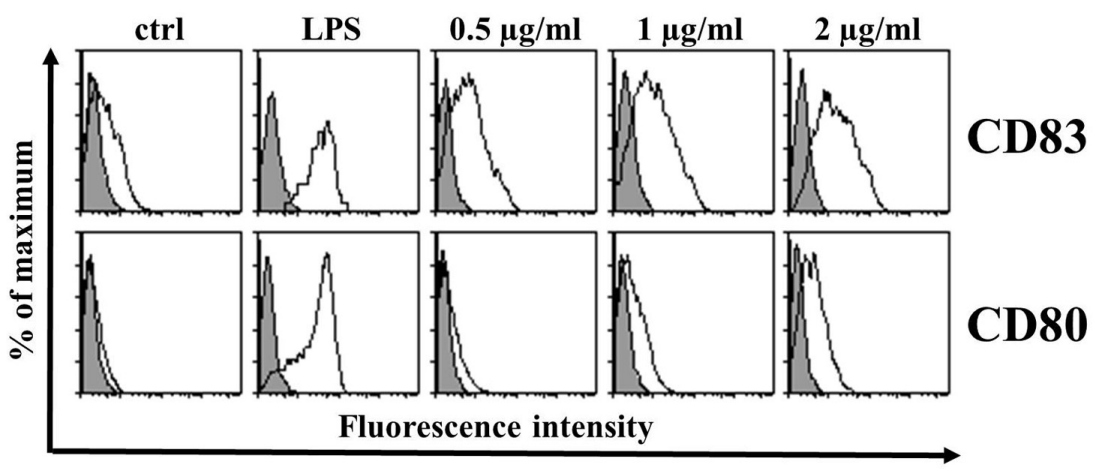

D

TNF- $\alpha$
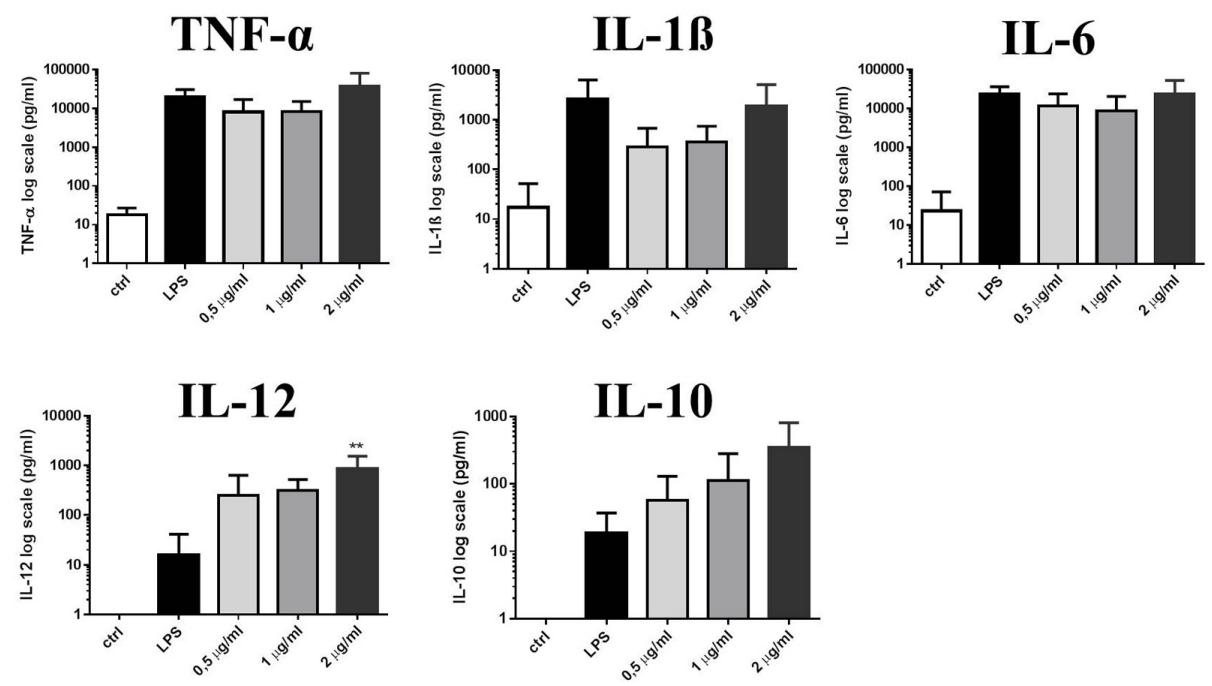

E

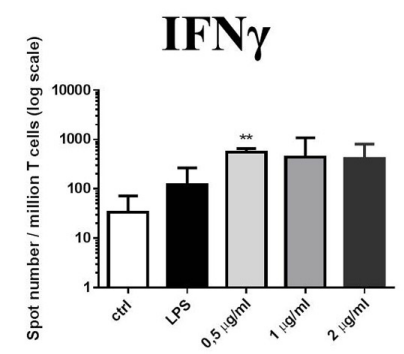

FIGURE 5 | Purified MUB protein triggers CD83 expression and induces Th1 polarized immune responses. Increasing concentrations of purified MUB was used to activate 2-day moDC cultures. LPS was used as a positive control. Cells were activated for $24 \mathrm{~h}$ and the cell surface expression of CD83 (A) and the co-stimulatory molecule CD80 (B) was measured by flow cytometry. Mean fluorescence intensity (MFI) and the ratio of CD83 positive cells were calculated from three independent experiments + SD. Histogram overlays are shown for one independent experiment (C). Production of inflammatory cytokines TNF $\alpha$, IL-1 $\beta$, IL-6, $\mathrm{IL}-12$ and the regulatory cytokine IL-10 in the supernatants of moDCs was detected after $24 \mathrm{~h}$ by ELISA. Mean values of cytokine concentrations were calculated from 3 independent experiments + SD (D). Freshly isolated PBLs were co-cultured with autologous moDCs for 4 days. The number of cytokine-producing PBLs in response to LPS as control or MUB-exposed human moDCs was measured by IFN $\gamma$ ELISPOT assay. Mean values of spot numbers were calculated from 3 independent experiments $\pm \mathrm{SD}(\mathbf{E})$. Statistical differences were analyzed by Student's $t$-test, with significance defined as ${ }^{*} P<0.05$, ${ }^{* *} P<0.01$, ${ }^{* * *} P<0.001$, and $* * * * P<0.0001$ 


\section{A}

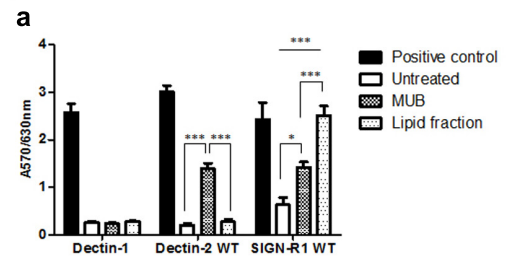

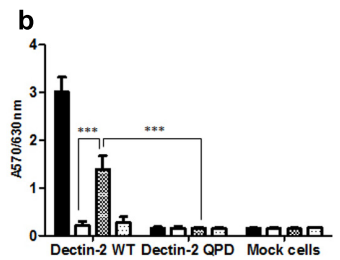

C

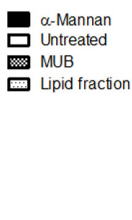

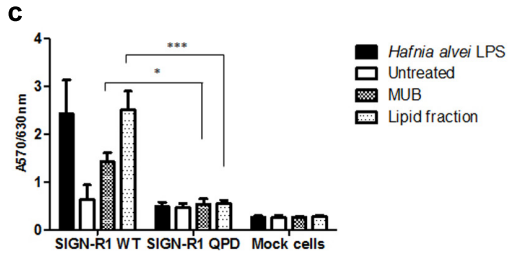

B

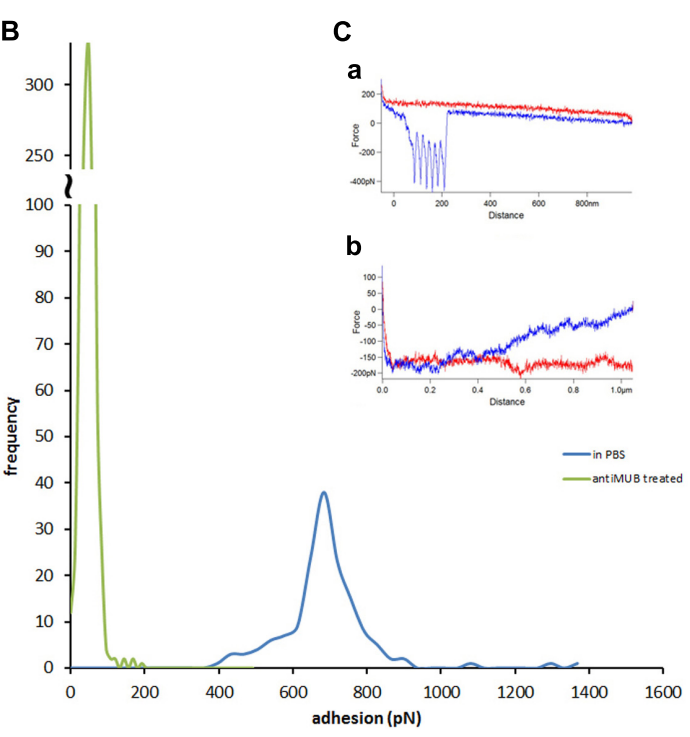

D
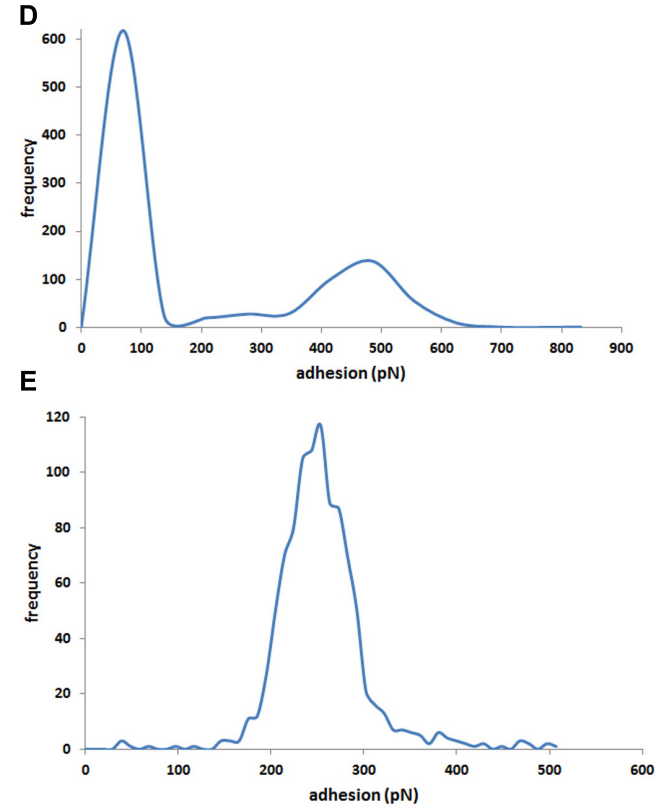

FIGURE 6 | Interaction of MUB with C-type lectin receptors. (A) Cell reporter assays were carried out to screen the interaction of MUB and MUB-derived lipid with CLRs (a), mDectin-2 and QPD-mutant reporter cells (b), SIGN-R1 and QPD-mutant reporter cells (c). Scleroglucan, $\alpha$-mannan, and Hafnia alvei LPS were used as a positive control for mDectin-1, mDectin-2, and SIGN-R1, respectively. Statistical differences were determined by ANOVA, with significance defined as * $P<0.05$, ${ }^{* *} P<0.01$, and ${ }^{* * *} P<0.001$. Force spectroscopy was used to measure the direct interaction between MUB functionalized AFM tip and CLRs. (B) Adhesion histograms between MUB and DC-SIGN. (C) Example of interaction force spectroscopy curves (Red - approach, Blue - retract) (a) MUB tip against DC-SIGN in PBS (b) MUB tip against DC-SIGN in presence of anti-Mub antibody. (D) Adhesion histogram of MUB and SIGNR1. (E) Adhesion histogram of MUB and Dectin-2.

surface proteins appeared to be important for the stimulation of THP-1 cells and the activation of NF- $\kappa B$ in U937-3xkBLUC cells by L. reuteri strains (Jensen et al., 2015). However, the specific mechanisms by which bacterial molecules could modulate cytokine expression in antigen-presenting cells remains to be identified.

Here we showed that host strain-specific adhesins contribute to the immunomodulatory effect of $L$. reuteri ATCC PTA 6475 and ATCC 53608 mediating (i) increased adherence and phagocytosis of $L$. reuteri strains by moDCs, (ii) enhanced CD83 expression, (iii) induced secretion of pro-inflammatory cytokines (TNF- $\alpha$, IL-1 $\beta$, IL-6) and that of the T-lymphocyte polarizing cytokines IL-12 and IL-23, and (iv) Th1 and Th17polarized immune responses characterized by IFN $\gamma$ and IL17 production, respectively. Both wild-type ATCC PTA 6475 and ATCC 53608 showed higher internalization by moDCs and increased expression of moDC activation markers as compared to the mucus adhesin mutant strains. However, strain-specific differences were observed in terms of cytokine production; TNF- $\alpha$ was induced preferentially in moDCs activated by the CmbA-expressing strain ATCC PTA 6475, while the MUB-expressing ATCC 53608 strain induced IL$1 \beta$ and IL-6 secretion. It is worth noting that $L$. reuteri ATCC PTA 6475 is generally considered as anti-inflammatory due to its reported ability to inhibit or down-regulate proinflammatory cytokines such as TNF- $\alpha$, MCP-1, IL- $1 \beta$, and IL-12 in stimulated myeloid cells (Lin et al., 2008), consistent with the known ability of L. reuteri strain ATCC PTA 6475 to suppress intestinal inflammation induced by LPS (Liu et al., 2010). Here we showed that, in absence of stimulatory signals mediated by LPS-induced PRRs, the immunogenicity of $L$. reuteri strains was increased by mucus-binding adhesins, and that the mutant strains showed a more tolerogenic immune response represented by decreased Th1 and Th17 immune responses, an effect which involves the CLR-induced signaling pathways in moDCs. 
A

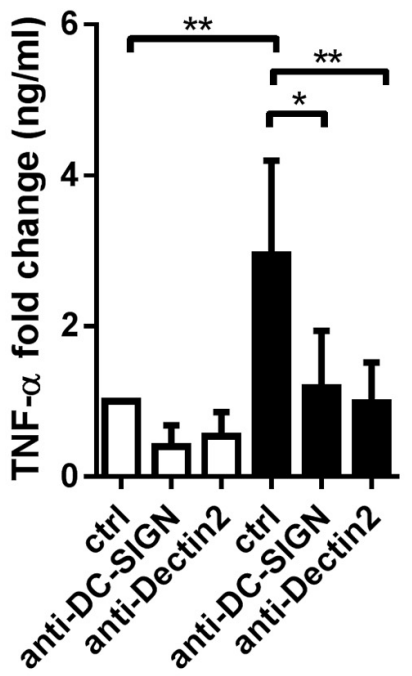

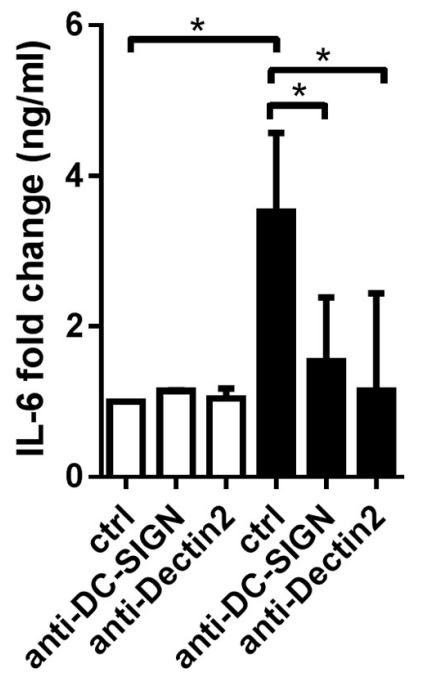

Without MUB

MUB-coated plastic

\section{в IFN $\gamma$}

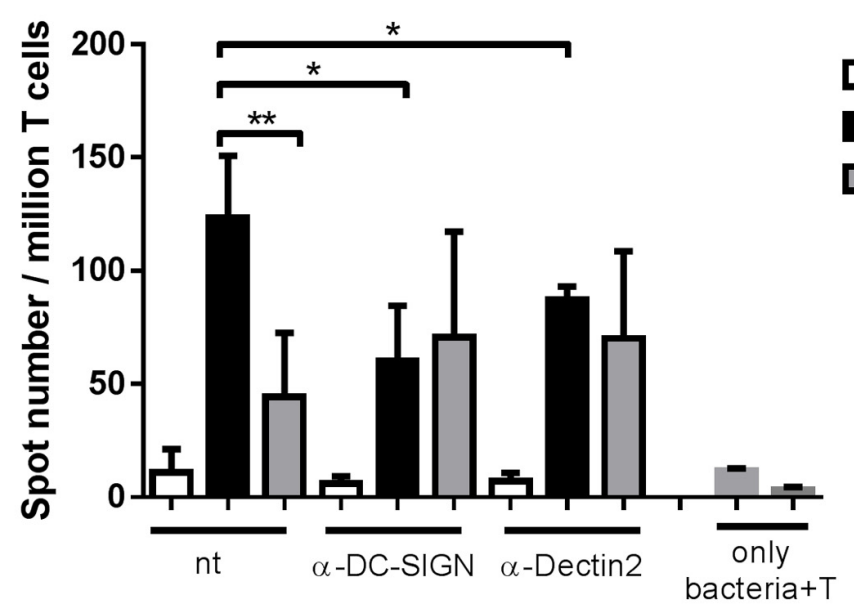

FIGURE 7 | The molecular background of bacterial MUB adhesin - moDC interaction causing inflammation and T-lymphocyte polarization. (A) MUB immobilized on a microtiter plate was incubated with 2-day moDC cultures treated with anti-Dectin-2 or anti-DC-SIGN antibodies. Unlabeled (ctrl) moDCs incubated on MUB-coated and uncoated wells served as negative and positive controls, respectively. The production of pro-inflammatory TNF- $\alpha$ and IL-6 cytokines was measured by ELISA after $24 \mathrm{~h}$. Mean value of cytokine concentrations was calculated from 5 independent experiments + SD. (B) MoDCs treated with anti-Dectin-2 or anti-DC-SIGN antibodies were co-cultured with live L. reuteri ATCC 53608 and $1063 \mathrm{~N}$ strains for $1.5 \mathrm{~h}$ at $37^{\circ} \mathrm{C}$, respectively. Freshly isolated PBLs were co-cultured with autologous moDCs for 4 days. The number of cytokine-producing T-cells was measured by IFN $\gamma$ ELISPOT assay. Mean values of spot numbers were calculated from 5 independent experiments + SD. T corresponds to T-cells cultured without dendritic cells as negative control. Statistical differences were analyzed by Student's $t$-test, with significance defined as ${ }^{*} P<0.05,{ }^{* *} P<0.01,{ }^{* * *} P<0.001$, and ${ }^{* * * *} P<0.0001$.

C-type lectin receptors represent one subset of PRRs expressed by a broad spectrum of cells (Meyer-Wentrup et al., 2005) and recognize a diverse range of endogenous and exogenous ligands including fungi, bacteria, parasites, and danger-associated molecular patterns driving both innate and adaptive immunity (Gijzen et al., 2006; Sukhithasri et al., 2013). The mechanism by which MUB exerts immunomodulatory effects was further investigated using a cell reporter assay specific for different CLRs showing that purified MUB from L. reuteri ATCC
53608 was recognized by mDectin- 2 and SIGN-R1 but not by mDectin-1. Dectin-1 is the major receptor on macrophages for $\beta$-1,3-glucan, a polymer of glucose present in the fungal cell wall (Herre et al., 2004) whereas Dectin-2, expressed by macrophages and various DC subsets recognizes high-mannose ligands found in diverse microbes, including Candida albicans (Zhu et al., 2013), Malassezia furfur (Ishikawa et al., 2013), and Schistosoma mansoni (Ritter et al., 2010). DC-SIGN (or CD209) is expressed in sub-epithelial DC subsets including $\mathrm{CD}^{+} \mathrm{c}^{+}$ 
and inflammatory DCs, both having the potential to modulate PRR-mediated signaling pathways (Soilleux, 2003; Geijtenbeek and Gringhuis, 2009). SIGN-R1, or CD209b, is one of the eight mouse homologs of human DC-SIGN (Park et al., 2001; Kang et al., 2003; Powlesland et al., 2006). These CLRs bind a broad variety of pathogenic microbial organisms and their polysaccharides (Geijtenbeek and Gringhuis, 2016) such as HIV virus (Geijtenbeek et al., 2000), mycobacteria (Geijtenbeek et al., 2003), C. albicans (Cambi et al., 2003; te Riet et al., 2015), Streptococcus pneumoniae (Kang et al., 2004) or Helicobacter pylori (Bergman et al., 2004) and serve as a target of penetration and infection in the host's cell while the specific immune response is prevented (van Kooyk et al., 2003). The direct interaction of MUB with DC-SIGN, SIGN-R1 and Dectin-2 was confirmed by atomic force spectroscopy. We clearly demonstrated that purified MUB, either in solution or immobilized, induced the secretion of inflammatory cytokines in moDCs. Furthermore, secretion of TNF- $\alpha$ and IL- 6 , but not IL-1 $\beta$ or IL-12, was reduced by the neutralization of the Dectin-2 and DC-SIGN-mediated inflammatory signaling pathways. These results suggest that the enhanced level of inflammatory Th1 and Th17 immune responses provoked by wild-type L. reuteri ATCC 53608 is dependent on the intimate interaction between MUB and the surface C-type lectin receptors of moDCs. Surprisingly, the uptake of L. reuteri ATCC 53608 was not affected in moDCs upon the selective blocking of DC-SIGN or Dectin-2. On the other hand, DC-SIGN and Dectin2 receptors played a crucial role in moDC-mediated Th1 type immune responses against $L$. reuteri ATCC 53608.

DC-SIGN present on immature DCs appears to be a general receptor for microbes leading to downstream $\mathrm{T}$ cell activation (Gijzen et al., 2007). DC-SIGN signaling stimulates tolerance responses in DCs, which is an important component in maintenance of homeostasis (Geijtenbeek and Gringhuis, 2009; Rabinovich, 2010; Wells, 2011) and can be elicited by specific lactobacilli (Penders et al., 2010) including strains of L. rhamnosus (Konieczna et al., 2015), L. acidophilus (Martínez et al., 2012), L. reuteri and L. casei (Smits et al., 2005). Interestingly, Lactobacillus cell surface proteins, such as L. rhamnosus proteinaceous pili (Tytgat et al., 2016) and L. acidophilus S-layer proteins (Konstantinov et al., 2008; Martínez et al., 2012; Prado Acosta et al., 2016) have recently been implicated in the interaction of Lactobacillus spp. with DC-SIGN. L. rhamnosus GG pili bind to mucus (Kankainen et al., 2009) and interact with macrophages (Vargas García et al., 2015). Recently, purified SpaCBA pili of L. rhamnosus GG were shown to directly interact with DC-SIGN in a carbohydratedependent manner and induce IL-6, IL-10, IL-12p40, and IL12p35 expression in DCs (Tytgat et al., 2016). The induction of these cytokines was partially dependent on DC-SIGN (Tytgat et al., 2016), in agreement with the reported impact of pili on TLR-2 signaling (Douillard et al., 2013; von Ossowski et al., 2013), which might be modulated by DC-SIGN, and the ability of $L$. rhamnosus GG wild-type and mutant strains to modulate several pro- and anti-inflammatory cytokines (Lebeer et al., 2012; von Ossowski et al., 2013; Vargas García et al., 2015). Our results indicated that TNF- $\alpha$ and IL- 6 secretion but no other inflammatory cytokines and chemokines was dependent on both Dectin-2 and DC-SIGN upon interaction with MUB, which suggest that other PRRs are also involved in this process. As far as we know, Dectin-2 has not been implicated in Lactobacillus immunomodulation (van Baarlen et al., 2013). Previous studies on fungal pathogens showed that the activation of Dectin-2 but not Dectin-1, led to the secretion of IL-23 and IL- $1 \beta$, supporting the polarization of Th17 cells (Gringhuis et al., 2011; Loures et al., 2015). Here, L. reuteri $1063 \mathrm{~N}$ mutant was less effective at inducing IL-1 $\beta$ secretion but no difference could be detected between the IL-23 secretion levels induced by the wild-type and the mutant $L$. reuteri strains. However, the prevention of molecular interaction between Dectin-2 and immobilized MUB reduced the production of IL6 , but not IL-1 $\beta$, in moDCs indicating that IL-6 may serve as a pivotal factor in L. reuteri ATCC 53608-induced Th17 polarization.

Taken together, these data provide novel insights into the mechanisms by which $L$. reuteri strains exert immunomodulatory properties via the direct interaction of $L$. reuteri host-specific adhesins with C-type lectins on DCs. The mucus-binding adhesins expressed on the surface of $L$. reuteri bacteria may contribute to the maintenance of the symbiotic relationship with the host by acting as a natural adjuvant, thus provoking antigen-specific adaptive immune responses by moDCs through the development of effector and memory T-lymphocytes with sufficient stimulatory potential. Further research is warranted to assess the pivotal role of protein-glycan interactions in the immunomodulatory capacities of probiotic strains.

\section{AUTHOR CONTRIBUTIONS}

KB carried out all moDc assays. DK purified MUB and glycolipid. CL carried out all CLR cell reporter assays. AW and IY established the reporter cells for Dectin-1 and SIGN-R1, IY performed the SIGN-R1 cell reporter assay with Hafnia-LPS. AG performed the AFM force spectroscopy assays. DM carried out the Lactobacillus reuteri growth cultures. NK supervised the CLR cell reporter assays. ER supervised the moDC assays. NJ coordinated the work and writing up of the manuscript

\section{ACKNOWLEDGMENTS}

The authors gratefully acknowledge the support of the Biotechnology and Biological Sciences Research Council (BBSRC), this research was partly funded by the BBSRC Institute Strategic Programme for The Gut Health and Food Safety (BB/J004529/1), Food and Health (BBS/E/F/00044486), the BB/K019554/1 BBSRC responsive mode grant, the IFR Strategy Fund Grant, the TORNADO FP7-KBBE-2007-2A: Molecular targets open for regulation by the gut flora: New avenues for improved diet to optimize European health, and by the European Union and the State of Hungary, co-financed by the European Social Fund in the framework of TÁMOP 4.2.4. A/2-11-1-2012-0001 'National Excellence Program' and TÁMOP 4.2.2.A-11/1/KONV-2012-0023. The authors thank 
Dr. Ewa Katzenellenbogen (Ludwik Hirszfeld Institute of Immunology and Experimental Therapy, Wroclaw, Poland) for providing Hafnia-LPS. NK acknowledges the Marie-Curie International Incoming Fellowship from the European Union 7th Framework Programme (Project ID: 628043).

\section{REFERENCES}

Bergman, M. P., Engering, A., Smits, H. H., van Vliet, S. J., van Bodegraven, A. A., Wirth, H. P., et al. (2004). Helicobacter pylori modulates the T helper cell 1/T helper cell 2 balance through phase-variable interaction between lipopolysaccharide and DC-SIGN. J. Exp. Med. 200, 979-990. doi: 10.1084/jem. 20041061

Bhatia, S. K., Shriver-Lake, L. C., Prior, K. J., Georger, J. H., Calvert, J. M., Bredehorst, R., et al. (1989). Use of thiol terminated silanes and heterobifunctional crosslinkers for immobilisation of antibodies on silica surfaces. Anal. Biochem. 178, 408-413. doi: 10.1016/0003-2697(89)90662-3

Call, E. K., Goh, Y. J., Selle, K., Klaenhammer, T. R., and O'Flaherty, S. (2015). Sortase-deficient lactobacilli: effect on immunomodulation and gut retention. Microbiology 161, 311-321. doi: 10.1099/mic.0.000007

Cambi, A., Gijzen, K., de Vries, 1. J, Torensma, R., Joosten, B., Adema, G. J., et al. (2003). The C-type lectin DC-SIGN (CD209) is an antigen-uptake receptor for Candida albicans on dendritic cells. Eur. J. Immunol. 33, 532-538. doi: 10.1002/immu.200310029

Carrion-Vazquez, M., Oberhauser, A. F., Fowler, S. B., Marszalek, P. E., Broedel, S. E., Clarke, J., et al. (1999). Mechanical and chemical unfolding of a single protein: a comparison. Proc. Natl. Acad. Sci. U.S.A. 96, 3694-3699. doi: 10.1073/ pnas.96.7.3694

Christensen, H. R., Frøkiaer, H., and Pestka, J. J. (2002). Lactobacilli differentially modulate expression of cytokines and maturation surface markers in murine dendritic cells. J. Immunol. 168, 171-178. doi: 10.4049/jimmunol.168. 1.171

Diebold, S. S. (2009). Activation of dendritic cells by toll-like receptors and C-type lectins. Handb. Exp. Pharmacol. 188, 3-30. doi: 10.1007/978-3-540-71029-5_1

Douillard, F. P., Ribbera, A., Jarvinen, H. M., Kant, R., Pietila, T. E., Randazzo, C., et al. (2013). Comparative genomic and functional analysis of Lactobacillus casei and Lactobacillus rhamnosus strains marketed as probiotics. Appl. Environ. Microbiol. 79, 1923-1933. doi: 10.1128/AEM.03467-12

Etzold, S., Kober, O. I., MacKenzie, D. A., Tailford, L. E., Gunning, A. P., Walshaw, J., et al. (2014a). Structural basis for adaptation of lactobacilli to gastrointestinal mucus. Environ. Microbiol. 16, 888-903. doi: 10.1111/14622920.12377

Etzold, S., MacKenzie, D. A., Jeffers, F., Walshaw, J., Roos, S., Hemmings, A. M., et al. (2014b). Structural and molecular insights into novel surface-exposed mucus adhesins from Lactobacillus reuteri human strains. Mol. Microbiol. 92, 543-556. doi: 10.1111/mmi.12574

Feng, T., Cong, Y., Alexander, K., and Elson, C. O. (2012). Regulation of Toll-like receptor 5 gene expression and function on mucosal dendritic cells. PLoS ONE 7:e35918. doi: 10.1371/journal.pone.0035918

Frese, S. A., Benson, A. K., Tannock, G. W., Loach, D. M., Kim, J., Zhang, M., et al. (2011). The evolution of host specialization in the vertebrate gut symbiont Lactobacillus reuteri. PLoS Genet. 7:e1001314. doi: 10.1371/journal. pgen.1001314

Frese, S. A., MacKenzie, D. A., Peterson, D. A., Schmaltz, R., Fangman, T., Zhou, Y., et al. (2013). Molecular characterization of host-specific biofilm formation in a vertebrate gut symbiont. PLoS Genet. 9:e1004057. doi: 10.1371/journal.pgen. 1004057

Gao, C., Major, A., Rendon, D., Lugo, M., Jackson, V., Shi, Z., et al. (2015). Histamine $\mathrm{H} 2$ receptor-mediated suppression of intestinal inflammation by probiotic Lactobacillus reuteri. MBio 6, e01358-15. doi: 10.1128/mBio. 01358-15

Geijtenbeek, T. B., and Gringhuis, S. I. (2009). Signalling through C-type lectin receptors: shaping immune responses. Nat. Rev. Immunol. 9, 465-479. doi: $10.1038 /$ nri2569

Geijtenbeek, T. B., and Gringhuis, S. I. (2016). C-type lectin receptors in the control of $\mathrm{T}$ helper cell differentiation. Nat. Rev. Immunol. 16, 433-448. doi: $10.1038 /$ nri.2016.55

\section{SUPPLEMENTARY MATERIAL}

The Supplementary Material for this article can be found online at: http://journal.frontiersin.org/article/10.3389/fmicb. 2017.00321/full\#supplementary-material

Geijtenbeek, T. B., Kwon, D. S., Torensma, R., van Vliet, S. J., van Duijnhoven, G. C., Middel, J., et al. (2000). DC-SIGN, a dendritic cell-specific HIV-1binding protein that enhances trans-infection of T cells. Cell 100, 587-597. doi: 10.1016/S0092-8674(00)80694-7

Geijtenbeek, T. B., Van Vliet, S. J., Koppel, E. A., Sanchez-Hernandez, M., Vandenbroucke-Grauls, C. M., Appelmelk, B., et al. (2003). Mycobacteria target DC-SIGN to suppress dendritic cell function. J. Exp. Med. 197, 7-17. doi: 10.1084/jem.20021229

Gijzen, K., Cambi, A., Torensma, R., and Figdor, C. G. (2006). C-type lectins on dendritic cells and their interaction with pathogen-derived and endogenous glycoconjugates. Curr. Protein Pept. Sci. 7, 283-294. doi: 10.2174/ 138920306778018016

Gijzen, K., Tacken, P. J., Zimmerman, A., Joosten, B., de Vries, I. J., Figdor, C. G., et al. (2007). Relevance of DC-SIGN in DC-induced T cell proliferation. J. Leukoc. Biol. 81, 729-740. doi: 10.1189/jlb.0606414

Gogolak, P., Rethi, B., Szatmari, I., Lanyi, A., Dezso, B., Nagy, L., et al. (2007). Differentiation of $\mathrm{CDla}^{-}$and $\mathrm{CDla}^{+}$monocyte-derived dendritic cells is biased by lipid environment and PPARgamma. Blood 109, 643-652. doi: 10 . 1182/blood-2006-04-016840

Griet, M., Zelaya, H., Mateos, M. V., Salva, S., Juarez, G. E., de Valdez, G. F., et al. (2014). Soluble factors from Lactobacillus reuteri CRL1098 have antiinflammatory effects in acute lung injury induced by lipopolysaccharide in mice. PLoS ONE 9:e110027. doi: 10.1371/journal.pone.0110027

Gringhuis, S. I., Wevers, B. A., Kaptein, T. M., van Capel, T. M., Theelen, B., Boekhout, T., et al. (2011). Selective C-Rel activation via Malt1 controls antifungal T(H)-17 immunity by dectin-1 and dectin-2. PLoS Pathog. 7:e1001259. doi: 10.1371/journal.ppat.1001259

Gunning, A. P., Chambers, S., Pin, C., Man, A. L., Morris, V. J., and Nicoletti, C. (2008). Mapping specific adhesive interactions on living human intestinal epithelial cells with atomic force microscopy. FASEB J. 22, 2331-2339. doi: 10.1096/fj.07-100578

Gyöngyösi, A., Szatmari, I., Pap, A., Dezso, B., Pos, Z., Széles, L., et al. (2013). RDH10, RALDH2, and CRABP2 are required components of PPAR $\gamma$-directed ATRA synthesis and signaling in human dendritic cells. J. Lipid Res. 54, 2458-2474. doi: 10.1194/jlr.M038984

Haileselassie, Y., Navis, M., Vu, N., Qazi, K. R., Rethi, B., and SverremarkEkström, E. (2016). Lactobacillus reuteri and Staphylococcus aureus differentially influence the generation of monocyte-derived dendritic cells and subsequent autologous T cell responses. Immun. Inflamm. Dis. 4, 315-326. doi: 10.1002/iid3.115

Herre, J., Gordon, S., and Brown, G. D. (2004). Dectin-1 and its role in the recognition of beta-glucans by macrophages. Mol. Immunol. 40, 869-876. doi: 10.1016/j.molimm.2003.10.007

Hinterdorfer, P., Gruber, H. J., Kienberger, F., Kada, G., Riener, C., Broken, C., et al. (2002). Surface attachment of ligands and receptors for molecular recognition force microscopy. Colloids Surf. B 23, 115-123. doi: 10.1016/S0927-7765(01) 00256-9

Hooper, L. V., and Macpherson, A. J. (2010). Immune adaptations that maintain homeostasis with the intestinal microbiota. Nat. Rev. Immunol. 10, 159-169. doi: $10.1038 /$ nri2 2710

Hou, C., Liu, H., Zhang, J., Zhang, S., Yang, F., Zeng, X., et al. (2015). Intestinal microbiota succession and immunomodulatory consequences after introduction of Lactobacillus reuteri 15007 in neonatal piglets. PLoS ONE 10:e0119505. doi: 10.1371/journal.pone.0119505

Hutter, J. L., and Bechhoefer, J. (1993). Calibration of atomic force microscope tips. Rev. Sci. Instrum. 64, 1868-1873. doi: 10.1063/1.1143970

Iliev, I. D., Spadoni, I., Mileti, E., Matteoli, G., Sonzogni, A., Sampietro, G. M., et al. (2009). Human intestinal epithelial cells promote the differentiation of tolerogenic dendritic cells. Gut 58, 1481-1489. doi: 10.1136/gut.2008.175166

Ishikawa, T., Itoh, F., Yoshida, S., Saijo, S., Matsuzawa, T., Gonoi, T., et al. (2013). Identification of distinct ligands for the C-type lectin receptors Mincle and 
Dectin-2 in the pathogenic fungus Malassezia. Cell Host Microbe 3, 477-488. doi: 10.1016/j.chom.2013.03.008

Jensen, H., Drømtorp, S. M., Axelsson, L., and Grimmer, S. (2015). Immunomodulation of monocytes by probiotic and selected lactic acid bacteria. Probiotics Antimicrob. Proteins 7, 14-23. doi: 10.1007/s12602-014-9174-2

Jensen, H., Roos, S., Jonsson, H., Rud, I., Grimmer, S., Van Pijkeren, J. P., et al. (2014). Role of Lactobacillus reuteri cell and mucus-binding protein A (CmbA) in adhesion to intestinal epithelial cells and mucus in vitro. Microbiology 160, 671-681. doi: 10.1099/mic.0.073551-0

Jones, S. E., and Versalovic, J. (2009). Probiotic Lactobacillus reuteri biofilms produce antimicrobial and anti-inflammatory factors. BMC Microbiol. 9:35. doi: 10.1186/1471-2180-9-35

Kang, Y. S., Kim, J. Y., Bruening, S. A., Pack, M., Charalambous, A., Pritsker, A., et al. (2004). The C-type lectin SIGN-R1 mediates uptake of the capsular polysaccharide of Streptococcus pneumoniae in the marginal zone of mouse spleen. Proc. Natl. Acad. Sci. U. S. A. 101, 215-220. doi: 10.1073/pnas. 0307124101

Kang, Y. S., Yamazaki, S., Iyoda, T., Pack, M., Bruening, S. A., Kim, J. Y., et al. (2003). SIGN-R1, a novel C-type lectin expressed by marginal zone macrophages in spleen, mediates uptake of the polysaccharide dextran. Int. Immunol. 15, 177-186. doi: 10.1093/intimm/dxg019

Kankainen, M., Paulin, L., Tynkkynen, S., von Ossowski, I., Reunanen, J., Partanen, P., et al. (2009). Comparative genomic analysis of Lactobacillus rhamnosus GG reveals pili containing a human-mucus binding protein. Proc. Natl. Acad. Sci. U.S.A. 106, 17193-17198. doi: 10.1073/pnas.0908876106

Konieczna, P., Schiavi, E., Ziegler, M., Groeger, D., Healy, S., Grant, R., et al. (2015). Human dendritic cell DC-SIGN and TLR-2 mediate complementary immune regulatory activities in response to Lactobacillus rhamnosus JB-1. PLoS ONE 10:e120261. doi: 10.1371/journal.pone.0120261

Konstantinov, S. R., Smidt, H., de Vos, W. M., Bruijns, S. C., Singh, S. K., Valence, F., et al. (2008). S layer protein A of Lactobacillus acidophilus NCFM regulates immature dendritic cell and T cell functions. Proc. Natl. Acad. Sci. U.S.A. 105, 19474-19479. doi: 10.1073/pnas.0810305105

Kotarski, S. F., and Savage, D. C. (1979). Models for study of the specificity by which indigenous lactobacilli adhere to murine gastric epithelia. Infect. Immun. 26, 966-975.

Kšonžeková, P., Bystrický, P., Vlčková, S., Pätoprstý, V., Pulzová, L., Mudroňová, D., et al. (2016). Exopolysaccharides of Lactobacillus reuteri: their influence on adherence of E. coli to epithelial cells and inflammatory response. Carbohydr. Polym. 141, 10-19. doi: 10.1016/j.carbpol.2015.12.037

Lebeer, S., Claes, I., Tytgat, H. L., Verhoeven, T. L., Marien, E., von Ossowski, I., et al. (2012). Functional analysis of Lactobacillus rhamnosus GG pili in relation to adhesion and immunomodulatory interactions with intestinal epithelial cells. Appl. Environ. Microbiol. 78, 185-193. doi: 10.1128/AEM.06192-11

Lebeer, S., Vanderleyden, J., and De Keersmaecker, S. C. (2008). Genes and molecules of lactobacilli supporting probiotic action. Microbiol. Mol. Biol. Rev. 72, 728-764. doi: 10.1128/MMBR.00017-08

Lin, Y. P., Thibodeaux, C. H., Peña, J. A., Ferry, G. D., and Versalovic, J. (2008). Probiotic Lactobacillus reuteri suppress proinflammatory cytokines via c-Jun. Inflamm. Bowel Dis. 14, 1068-1083. doi: 10.1002/ibd.20448

Liu, Y., Fatheree, N. Y., Mangalat, N., and Rhoads, J. M. (2010). Humanderived probiotic Lactobacillus reuteri strains differentially reduce intestinal inflammation. Am. J. Physiol. Gastrointest. Liver Physiol. 299, G1087-G1096. doi: 10.1152/ajpgi.00124.2010

Livingston, M., Loach, D., Wilson, M., Tannock, G. W., and Baird, M. (2010). Gut commensal Lactobacillus reuteri 100-23 stimulates an immunoregulatory response. Immunol. Cell Biol. 88, 99-102. doi: 10.1038/icb. 2009.71

Loures, F. V., Röhm, M., Lee, C. K., Santos, E., Wang, J. P., Specht, C. A., et al. (2015). Recognition of Aspergillus fumigatus hyphae by human plasmacytoid dendritic cells is mediated by dectin-2 and results in formation of extracellular traps. PLoS Pathog. 11:e1004643. doi: 10.1371/journal.ppat.1004643

MacKenzie, D. A., Jeffers, F., Parker, M. L., Vibert-Vallet, A., Bongaerts, R. J., Roos, S., et al. (2010). Strain-specific diversity of mucus-binding proteins in the adhesion and aggregation properties of Lactobacillus reuteri. Microbiology 156, 3368-3378. doi: 10.1099/mic.0.043265-0

MacKenzie, D. A., Tailford, L. E., Hemmings, A. M., and Juge, N. (2009). Crystal structure of a mucus-binding protein repeat reveals an unexpected functional immunoglobulin binding activity. J. Biol. Chem. 284, 32444-32453. doi: 10.1074/jbc.M109.040907

Mann, E. R., and Li, X. (2014). Intestinal antigen-presenting cells in mucosal immune homeostasis: crosstalk between dendritic cells, macrophages and B-cells. World J. Gastroenterol. 20, 9653-9664. doi: 10.3748/wjg.v20. i29.9653

Martínez, M. G., Prado Acosta, M., Candurra, N. A., and Ruzal, S. M. (2012). S-layer proteins of Lactobacillus acidophilus inhibits JUNV infection. Biochem. Biophys. Res. Commun. 422, 590-595. doi: 10.1016/j.bbrc.2012.05.031

Mechoud, M. A., Mateos, M. V., de Valdez, G. F., Villena, J., Salvador, G. A., and Rodriguez, A. V. (2012). Lactobacillus reuteri CRL1098 soluble factors modulate tumor necrosis factor alpha production in peripheral blood mononuclear cells: involvement of lipid rafts. Int. Immunopharmacol. 14, 446-453. doi: 10.1016/j. intimp.2012.08.020

Meijerink, M., van Hemert, S., Taverne, N., Wels, M., de Vos, P., Bron, P. A., et al. (2010). Identification of genetic loci in Lactobacillus plantarum that modulate the immune response of dendritic cells using comparative genome hybridization. PLoS ONE 5:e10632. doi: 10.1371/journal.pone.0010632

Meyer-Wentrup, F., Cambi, A., Adema, G. J., and Figdor, C. G. (2005). "Sweet talk": closing in on C type lectin signaling. Immunity 22, 399-400. doi: 10.1016/ j.immuni.2005.04.001

Oh, P. L., Benson, A. K., Peterson, D. A., Patil, P. B., Moriyama, E. N., Roos, S., et al. (2010). Diversification of the gut symbiont Lactobacillus reuteri as a result of host-driven evolution. ISME J. 4, 377-387. doi: 10.1038/ismej.2009.123

Park, C. G., Takahara, K., Umemoto, E., Yashima, Y., Matsubara, K., Matsuda, Y., et al. (2001). Five mouse homologues of the human dendritic cell C-type lectin, DC-SIGN. Int. Immunol. 13, 1283-1290. doi: 10.1093/intimm/13. 10.1283

Peña, J. A., Rogers, A. B., Ge, Z., Ng, V., Li, S. Y., Fox, J. G., et al. (2005). Probiotic Lactobacillus spp. diminish Helicobacter hepaticus-induced inflammatory bowel disease in interleukin-10-deficient mice. Infect. Immun. 73, 912-920. doi: 10.1128/IAI.73.2.912-920.2005

Penders, J., Thijs, C., Mommers, M., Stobberingh, E. E., Dompeling, E., Reijmerink, N. E., et al. (2010). Intestinal lactobacilli and the DC-SIGN gene for their recognition by dendritic cells play a role in the aetiology of allergic manifestations. Microbiology 156, 3298-3305. doi: 10.1099/mic.0. 042069-0

Persson, E. K., Scott, C. L., Mowat, A. M., and Agace, W. W. (2013). Dendritic cell subsets in the intestinal lamina propria: ontogeny and function. Eur. J. Immunol. 43, 3098-3107. doi: 10.1002/eji.201343740

Powlesland, A. S., Ward, E. M., Sadhu, S. K., Guo, Y., Taylor, M. E., and Drickamer, K. (2006). Widely divergent biochemical properties of the complete set of mouse DC-SIGN-related proteins. J. Biol. Chem. 281, 20440-20449. doi: 10.1074/jbc.M601925200

Prado Acosta, M., Ruzal, S. M., and Cordo, S. M. (2016). S-layer proteins from Lactobacillus sp. inhibit bacterial infection by blockage of DC-SIGN cell receptor. Int. J. Biol. Macromol. 92, 998-1005. doi: 10.1016/j.ijbiomac.2016. 07.096

Rabinovich, G. A. (2010). A sweet path toward tolerance in the gut. Nat. Med. 16, 1076-1077. doi: 10.1038/nm1010-1076

Regulski, K., Courtin, P., Meyrand, M., Claes, I. J., Lebeer, S., Vanderleyden, J., et al. (2012). Analysis of the peptidoglycan hydrolase complement of Lactobacillus case $i$ and characterization of the major $\gamma$-D-glutamyl-L-lysyl-endopeptidase. PLoS ONE 7:e32301. doi: 10.1371/journal.pone.0032301

Remus, D. M., Bongers, R. S., Meijerink, M., Fusetti, F., Poolman, B., de Vos, P., et al. (2013). Impact of Lactobacillus plantarum sortase on target protein sorting, gastrointestinal persistence, and host immune response modulation. J. Bacteriol. 195, 502-509. doi: 10.1128/JB.01321-12

Rescigno, M. (2014). Dendritic cell-epithelial cell crosstalk in the gut. Immunol. Rev. 260, 118-128. doi: 10.1111/imr.12181

Rescigno, M., Urbano, M., Valzasina, B., Francolini, M., Rotta, G., Bonasio, R., et al. (2001). Dendritic cells express tight junction proteins and penetrate gut epithelial monolayers to sample bacteria. Nat. Immunol. 2, 361-367. doi: $10.1038 / 86373$

Ritter, M., Gross, O., Kays, S., Ruland, J., Nimmerjahn, F., Saijo, S., et al. (2010). Schistosoma mansoni triggers Dectin-2, which activates the Nlrp3 inflammasome and alters adaptive immune responses. Proc. Natl. Acad. Sci. U.S.A. 107, 20459-20464. doi: 10.1073/pnas. 1010337107 
Roos, S., and Jonsson, H. (2002). A high-molecular-mass cell-surface protein from Lactobacillus reuteri 1063 adheres to mucus components. Microbiology 148, 433-442. doi: 10.1099/00221287-148-2-433

Smits, H. H., Engering, A., van der Kleij, D., de Jong, E. C., Schipper, K., van Capel, T. M., et al. (2005). Selective probiotic bacteria induce IL-10producing regulatory $\mathrm{T}$ cells in vitro by modulating dendritic cell function through dendritic cell-specific intercellular adhesion molecule 3-grabbing nonintegrin. J. Allergy Clin. Immunol. 115, 1260-1267. doi: 10.1016/j.jaci.2005. 03.036

Soilleux, E. J. (2003). DC-SIGN (dendritic cell-specific ICAM-grabbing nonintegrin) and DC-SIGN-related (DC-SIGNR): friend or foe? Clin. Sci. (Lond.) 104, 437-446. doi: 10.1042/cs1040437

Spinler, J. K., Sontakke, A., Hollister, E. B., Venable, S. F., Oh, P. L., Balderas, M. A., et al. (2014). From prediction to function using evolutionary genomics: humanspecific ecotypes of Lactobacillus reuteri have diverse probiotic functions. Genome Biol. Evol. 6, 1772-1789. doi: 10.1093/gbe/evu137

Sukhithasri, V., Nisha, N., Biswas, L., Anil Kumar, V., and Biswas, R. (2013). Innate immune recognition of microbial cell wall components and microbial strategies to evade such recognitions. Microbiol. Res. 168, 396-406. doi: 10.1016/j.micres. 2013.02.005

Sun, J., and Chang, E. B. (2014). Exploring gut microbes in human health and disease: pushing the envelope. Genes Dis. 1, 132-139. doi: 10.1016/j.gendis.2014. 08.001

Szatmari, I., Pap, A., Rühl, R., Ma, J. X., Illarionov, P. A., Besra, G. S., et al. (2006). PPARgamma controls CD1d expression by turning on retinoic acid synthesis in developing human dendritic cells. J. Exp. Med. 203, 2351-2362. doi: $10.1084 /$ jem.20060141

te Riet, J., Reinieren-Beeren, I., Figdor, C. G., and Cambi, A. (2015). AFM force spectroscopy reveals how subtle structural differences affect the interaction strength between Candida albicans and DC-SIGN. J. Mol. Recognit. 28, 687-698. doi: 10.1002/jmr.2481

Tytgat, H. L., van Teijlingen, N. H., Sullan, R. M., Douillard, F. P., Rasinkangas, P., Messing, M., et al. (2016). Probiotic gut microbiota isolate interacts with dendritic cells via glycosylated heterotrimeric pili. PLoS ONE 11:e0151824. doi: 10.1371/journal.pone.0151824

Valeur, N., Engel, P., Carbajal, N., Connolly, E., and Ladefoged, K. (2004). Colonization and immunomodulation by Lactobacillus reuteri ATCC 55730 in the human gastrointestinal tract. Appl. Environ. Microbiol. 70, 1176-1181. doi: 10.1128/AEM.70.2.1176-1181.2004

van Baarlen, P., Wells, J. M., and Kleerebezem, M. (2013). Regulation of intestinal homeostasis and immunity with probiotic lactobacilli. Trends Immunol. 34, 208-215. doi: 10.1016/j.it.2013.01.005

van Kooyk, Y., Appelmelk, B., and Geijtenbeek, T. B. (2003). A fatal attraction: mycobacterium tuberculosis and HIV-1 target DC-SIGN to escape immune surveillance. Trends Mol. Med. 9, 153-159. doi: 10.1016/S1471-4914(03) 00027-3

Vargas García, C. E., Petrova, M., Claes, I. J., De Boeck, I., Verhoeven, T. L., Dilissen, E., et al. (2015). Piliation of Lactobacillus rhamnosus
GG promotes adhesion, phagocytosis, and cytokine modulation in macrophages. Appl. Environ. Microbiol. 81, 2050-2062. doi: 10.1128/AEM. 03949-14

von Ossowski, I., Pietilä, T. E., Rintahaka, J., Nummenmaa, E., Mäkinen, V. M., Reunanen, J., et al. (2013). Using recombinant Lactococci as an approach to dissect the immunomodulating capacity of surface piliation in probiotic Lactobacillus rhamnosus GG. PLoS ONE 8:e64416. doi: 10.1371/journal.pone. 0064416

Walter, J., Britton, R. A., and Roos, S. (2011). Host-microbial symbiosis in the vertebrate gastrointestinal tract and the Lactobacillus reuteri paradigm. Proc. Natl. Acad. Sci. U.S.A. 108(Suppl. 1), 4645-4652. doi: 10.1073/pnas.1000099107

Walter, J., and Ley, R. (2011). The human gut microbiome: ecology and recent evolutionary changes. Annu. Rev. Microbiol. 65, 411-429. doi: 10.1146/ annurev-micro-090110-102830

Wegmann, U., MacKenzie, D. A., Zheng, J., Goesmann, A., Roos, S., Swarbreck, D., et al. (2015). The pan-genome of Lactobacillus reuteri strains originating from the pig gastrointestinal tract. BMC Genomics 16:1023. doi: 10.1186/s12864-0152216-7

Wells, J. M. (2011). Immunomodulatory mechanisms of lactobacilli. Microb. Cell Fact. 10:S17. doi: 10.1186/1475-2859-10-S1-S17

Wittmann, A., Lamprinaki, D., Bowles, K. M., Katzenellenbogen, E., Knirel, Y. A., Whitfield, C., et al. (2016). Dectin-2 recognizes mannosylated O-antigens of human opportunistic pathogens and augments lipopolysaccharide activation of myeloid cells. J. Biol. Chem. 291, 17629-17638. doi: 10.1074/jbc.M116. 741256

Zhang, J. P., Wang, Q., Smith, T. R., Hurst, W. E., and Sulpizio, T. (2005). Endotoxin removal using a synthetic adsorbent of crystalline calcium silicate hydrate. Biotechnol. Prog. 21, 1220-1225. doi: 10.1021/bp0500359

Zhu, L. L., Zhao, X. Q., Jiang, C., You, Y., Chen, X. P., Jiang, Y. Y., et al. (2013). C-type lectin receptors Dectin-3 and Dectin-2 form a heterodimeric patternrecognition receptor for host defense against fungal infection. Immunity 39, 324-334. doi: 10.1016/j.immuni.2013.05.017

Conflict of Interest Statement: The authors declare that the research was conducted in the absence of any commercial or financial relationships that could be construed as a potential conflict of interest.

The reviewer ADAF and handling Editor declared their shared affiliation, and the handling Editor states that the process nevertheless met the standards of a fair and objective review.

Copyright (c) 2017 Bene, Kavanaugh, Leclaire, Gunning, MacKenzie, Wittmann, Young, Kawasaki, Rajnavolgyi and Juge. This is an open-access article distributed under the terms of the Creative Commons Attribution License (CC BY). The use, distribution or reproduction in other forums is permitted, provided the original author(s) or licensor are credited and that the original publication in this journal is cited, in accordance with accepted academic practice. No use, distribution or reproduction is permitted which does not comply with these terms. 